UCRL-ID-133251

\title{
Lung Cancer Risk of Low-Level Exposures to Alpha Emitters: Critical Reappraisal and Experiments Based on a New Cytodynamic Model
}

\author{
K. T. Bogen
}

February 20, 1999

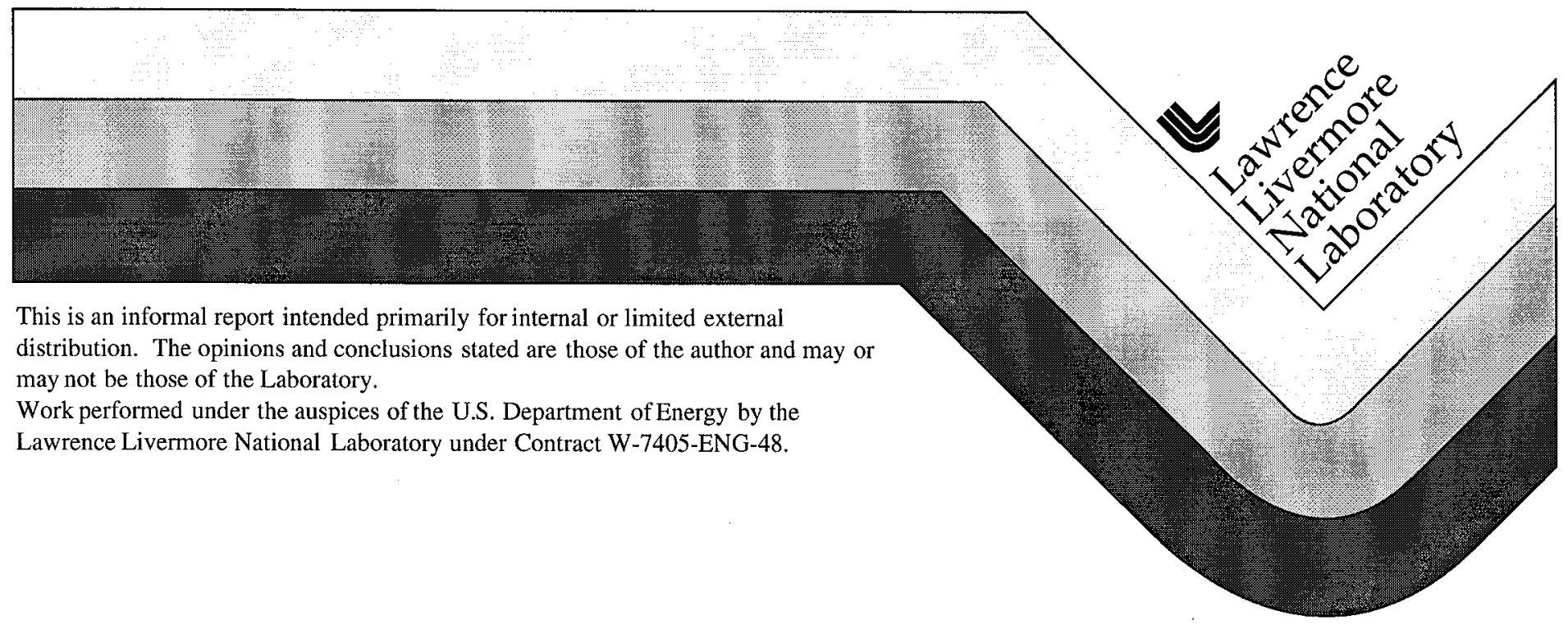




\section{DISCLAIMER}

This document was prepared as an account of work sponsored by an agency of the United States Government. Neither the United States Government nor the University of California nor any of their employees, makes any warranty, express or implied, or assumes any legal liability or responsibility for the accuracy, completeness, or usefulness of any information, apparatus, product, or process disclosed, or represents that its use would not infringe privately owned rights. Reference herein to any specific commercial product, process, or service by trade name, trademark, manufacturer, or otherwise, does not necessarily constitute or imply its endorsement, recommendation, or favoring by the United States Government or the University of California. The views and opinions of authors expressed herein do not nccessarily state or reflect those of the United States Government or the University of California, and shall not be used for advertising or product endorsement purposes.

This report has been reproduced directly from the best available copy.

Available to DOE and DOE contractors from the

Office of Scientific and Technical Information

P.O. Box 62, Oak Ridge, TN 37831

Prices available from (423) 576-8401

Available to the public from the

National Technical Information Service

U.S. Department of Commerce

5285 Port Royal Rd.,

Springficld, VA 22161 


\title{
Lung Cancer Risk of Low-Level Exposures to Alpha Emitters: Critical Reappraisal and Experiments Based on a New Cytodynamic Model
}

\author{
Final Report on LDRD Project 97-ERD-050
}

\author{
Dr. Kenneth T. Bogen, Principal Investigator \\ Lawrence Livermore National Laboratory, \\ University of California, Livermore, $\mathrm{CA}^{*}$
}

February 20, 1999

*Health and Ecological Assessment Div. (L-396), Lawrence Livermore National Laboratory, Livermore, CA 94550, USA, Tel: (925) 422-0902, Fax: (925) 424-3255, EMAIL: bogen@LLNL.gov. 


\section{Summary}

Ecologic U.S. county data suggest negative associations between residential radon exposure and lung cancer mortality (LCM)-inconsistent with clearly positive associations revealed by occupational data on individual miners, but perhaps explained by competing effects of cell killing vs. mutations in alpha-exposed bronchial epithelium. To assess the latter possibility, a biologically based "cytodynamic 2-stage" (CD2) cancer-risk model was fit to combined 1950-54 agespecific person-year data on lung cancer mortality (LCM) in white females of age 40+ $y$ in 2,821 U.S. counties ( $90 \%$ never-smokers), and in 5 cohorts of underground miners who never smoked. New estimates of household annual average radon exposure in U.S. counties were used, which were found to have a significant negative ecologic association with 1950-54 LCM in U.S. white females, adjusted for age and all subsets of two among 21 socioeconomic, climatic and other factors considered. A good CD2 fit was obtained to the combined residential/miner data, using biologically plausible parameter values. Without further optimization, the fit also predicted independent inverse dose-rate effects shown (for the first time) to occur in nonsmoking miners. Using the same U.S. county-level LCM data, a separate study revealed a positive ecologic association between LCM and bituminous coal use in the U.S., in agreement with epidemiological data on LCM in women in China. The modeling results obtained are consistent with the CD2-based hypothesis that residential radon exposure has a nonlinear U-shaped relation to LCM risk, and that current linear no-threshold extrapolation models substantially overestimate such risk. A U-shaped dose-response corresponds to a CD2-model prediction that alpha radiation kills more premalignant cells than it generates at low exposure levels, but not at higher levels. To test this hypothesis, groups of Japanese medaka (ricefish minnows) were exposed for 10 to 14 weeks to different concentrations of aqueous radon; histological and quantitative-morphometry analysis of proliferative (premalignant) foci in livers from these fish are currently being completed. 


\section{Acknowledgments}

This work was performed under the auspices of the U.S. Department of Energy at Lawrence Livermore National Laboratory (LLNL) under contract W-7405-ENG-48, with LDRD support from the Earth and Environmental Sciences Directorate. I am grateful to Dr. J. Lubin and coworkers for access to miner data; to Dr. P. Price (Lawrence Berkeley National Laboratory) for access to updated radon estimates and an analysis of inter-county radon variance (included as Appendix 2 of the present report); to Jennifer Cullen (doctoral candidate at University of California Berkeley, Department of Epidemiology and Biostatistics) who coauthored material contained and referenced herein relating lung cancer and exposure to bituminous coal; to Dr. J. Mumford for information on Chinese coal research, and to L. Wilder and C. Hall (LLNL Geographic Information Systems [GIS] Center) for geographic database support. I am very grateful to A. Biermann at LLNL for providing the $10-\mathrm{mCi}$ radium source he designed and had constructed, which was used to expose fish to radon gas in an experiment carried out in collaboration with Dr. M. Okihiro and Professor D. Hinton of the University of California Davis School of Veterinary Medicine, to whom I am also grateful. This collaborative experiment could not have been undertaken at LLNL without outstanding support for related healthphysics and operational-safety issues provided by LLNL staff, including A. Biermann, S. Sawyer, B. Buddemeier, S. Laureta, T. Biggs, R. Lippe, M. Costella, D. Lima; the experiment was also made possible by sustained efforts of LLNL technicans S. Martins in particular, as well as C. Fry, in designing, installing and maintaining the radon/air-flow and related systems used, and of LLNL nuclear chemist E.B. Guthrie who measured radon concentrations in samples of tank water. Special thanks also go to LLNL colleagues L. Hall, S. Martins, and Dr. G. Keating for laboratory work supporting the medaka experiment, and to Drs. D.A. Canter, L.C. Clark, and G. Keating for assistance obtaining information concerning the geographic distribution of selenium in U.S. counties. 


\section{Table of Contents}

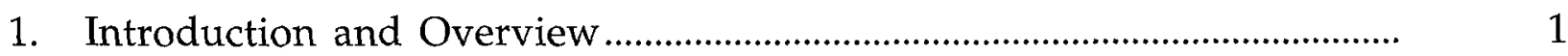

2. Investigation of a Mechanistic Model Relating Radon Exposure to Lung-Cancer Risk Reflected in Combined Occupational and U.S.

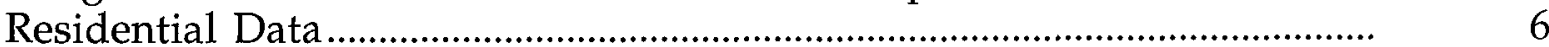

2.1. Background ..........................................................................................

2.2. Materials and Methods..............................................................................

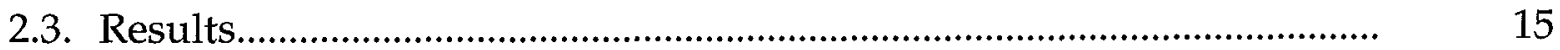

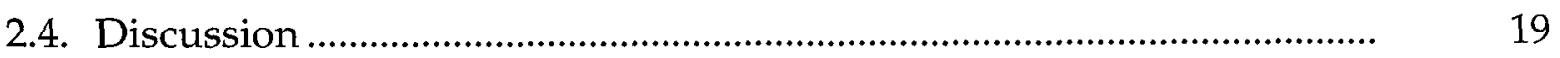

3. Historical U.S. Residential Fuel Use and Female Lung Cancer Mortality 27

3.1. Background ......................................................................................... 27

3.2. Materials and Methods..........................................................................

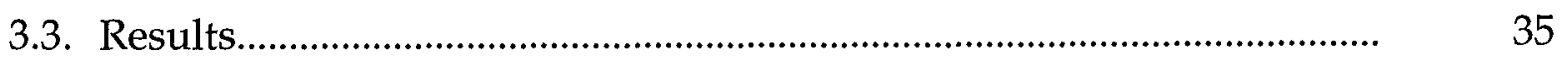

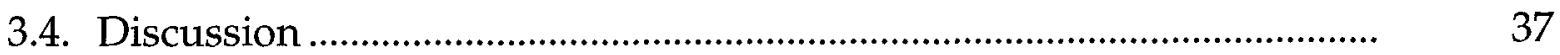

4. Effect of Radon Exposure on Liver Foci in Japanese Medaka: An Experimental Test of CD2-Model Predictions ................................................ 40

4.1. Background .......................................................................................... 40

4.2. Materials and Methods............................................................................. 41

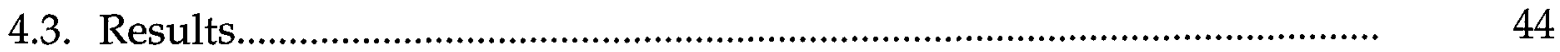

5. Conclusions ................................................................................................ 44

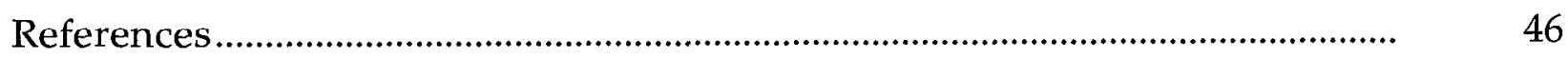

Appendix 1. Mathematical Details of the CD2 Mode1........................................... 56

Appendix 2. Estimated distributions of county GSDs of indoor radon concentrations 


\section{Introduction and Overview}

This report describes the focus, methods and results of three related research efforts undertaken during FY97-FY98 comprising LLNL LDRD Project 97-ERD-050. These three research efforts concerned: (1) application of a mechanistic, biologically based cancer-risk model to apparently contradictory epidemiological data relating lung-cancer mortality (LCM) to residential and occupational exposures to radon gas; (2) a parallel assessment of whether the same U.S. county-level LCM data used for the latter analysis revealed an expected positive association between LCM and lifetime use of bituminous coal for residential heating; and (3) an experimental test of a biologically based hypothesis that premalignant-cell number (and by implication, cancer risk) may have a nonlinear dose-response relation to alpha radiation. An introduction and overview of these three efforts is provided below, followed by detailed descriptions in Sections 2, 3 and 4 of this report.

The present LDRD research project stemmed from the observation that a new, cytodynamic two-stage (CD2) cancer model developed at LLNL was able to predict two apparently contrasting data sets relating lung-cancer mortality (LCM) to radon exposure (Bogen, 1997). First, the model predicted a negative dose-response trend when previously published U.S. county-level data on mean residential radon exposures were compared to data on age-adjusted 1980s LCM in white males (both smokers and nonsmokers); second, the model predicted a positive dose-response trend when summary information on cumulative occupational radon exposure was compared to previously published summary LCM estimates for underground miners working on the Colorado Plateau. That both data sets were fit using one set 
of biologically realistic $\mathrm{CD} 2$-parameter values suggested that low-level radon may actually reduce lung cancer risk, that is, that the negative ecologic association between radon and LCM risk may be biologically plausible, in view of the mechanistically realistic two-stage carcinogenesis theory on which the CD2 model is based. The CD2 model's prediction is based on the expectation of competing effects on cancer risk due to critical DNA damage vs. cell killing caused by the alpha irradiation of bronchial surface epithelium associated with the radioactive decay of naturally occurring radon gas. Specifically, in the case of radiation due to exposures to the small concentrations of radon gas typically found in U.S. homes, this radiation may kill enough premalignant cells to more than offset radiation-induced occurrence of new premalignant cells. Higher levels of radiation, however, are expected to increase lung-cancer risk by inducing the replacement of killed surface cells via proliferation of underlying stem cells, which in turn promotes the clonal expansion of any pre-existing "spontaneous" premalignant cells within the underlying (and relatively unexposed) stem cells.

Although biologically plausible, the preliminary CD2 modeling results (Bogen, 1997) relied entirely on a previously published summary of age-adjusted LCM and radon-exposure data, as well as on summary (rather than individual-level) data on LCM in Colorado Plateau uranium miners. The preliminary study also estimated the amount of cell killing caused by alpha radiation by means of fitting the CD2model to LCM data, rather than using published estimates from in vitro experiments involving alpha-exposed human lung cells. 
The primary goal of the present research project, therefore, was to refit the CD2 model for radon to sets of epidemiological data different than those used initially by Bogen (1987) - data that better address the estimation of radon concentrations in U.S. homes, as well as potentially confounding effects of smoking on the interpretation of radon-LCM associations. Specially, the limitations mentioned above were addressed by refitting the CD2 model, conditional on likely alpha cytotoxicity, to age-specific LCM data for white females of age $40+y$ in 2,821 U.S. counties during 1950-54 ( $90 \%$ of whom never smoked). Entirely new estimates of county-specific mean residential radon levels were used, together with age-specific (not age-adjusted) LCM data obtained for five cohorts of underground miners who never smoked.

During FY97, we assembled new data on age-specific LCM data and estimated corresponding residential radon concentrations in white females of age $40+y$ (about $11 \%$ of whom ever smoked) in 2,821 U.S. counties during 1950-54, and in five different groups of underground miners (a total of 2,488 miners worldwide) who never smoked. The county-level LCM data for white women in the early 1950s, previously unavailable in any form, were generated from raw U.S. mortality data specifically for this study. We used new estimates of county-specific mean residential radon levels for all U.S. counties recently generated by Lawrence Berkeley National Laboratory (LBNL). In collaboration with LLNL, LBNL performed uncertainty analyses pertaining to the new radon estimates used. A data base of corresponding county-level census, climatological, and geophysical data were also assembled at LLNL. Person-year data summarizing individual-level exposure 
and LCM information on nonsmoking miners were obtained through the National Cancer Institute.

Research during FY98 began with a trend-analysis of the improved "ecologic"type epidemiological data, followed by a refit of the CD2 model to thesc data (Bogen, 1998). The trend analysis revealed that radon levels were found to be significantly negatively associated with corresponding county-level LCM rates in U.S. women who died in 1950-54 at age 40+ or 60+ years, after adjustment for age and subsets of 21 other factors considered. A similarity in results obtained for $40+$ and $60+$ yearolds indicates that inter-county differences in smoking are unlikely to explain the observed negative associations. A good CD2 fit was obtained to the combined residential and occupational data involving $>50$ data points relating radon exposure to age-specific LCM. This fit also happens also to predict the so-called "inverse doserate" effect observed previously in underground miners-but now shown-for the first time-also to occur in nonsmoking miners in particular (Bogen, 1998). Specifically, the CD2 fit obtained in this study predicts independent data to which the CD2 model was not fit-a result similar to that found previously using data on combined smoking and nonsmoking miners (Bogen, 1997). The results of this study are consistent with the hypothesis that residential radon exposure has a nonlinear, U-shaped relation to LCM risk, and that current linear extrapolation models may substantially overestimate such risk (Bogen, 1998).

A parallel analysis was also conducted to determine whether, using the same county-level data on LCM in white U.S. women during 1950-54 and corresponding geophysical/socioeconomic/climatic covariates generated for this study, an expected 
positive ecologic association could be discerned between LCM and domestic exposure to bituminous coal (BC). Ecologic and case-control epidemiological studies on populations of women in China have shown a strong link between domestic BC exposure and lung cancer, but this association had never been studied in any U.S. population. For this purpose, historical county-level data on U.S. domestic BT use were obtained, and these data were compared to our corresponding LCM data for all counties in which $50 \%$ or more of homes used coal for heating. We found that $\mathrm{BC}$ use was-as expected-significantly positively associated with corresponding county-level LCM rates in U.S. women dying in 1950-54 at age $40+$ or $60+$ years, after adjustment for age and many other factors considered (Cullen and Bogen, 1998).

Experimental work was also conducted as part of this LDRD-sponsored project, in collaboration with Drs. M. Okihiro and D. Hinton of the University of California, Davis (U.C. Davis), School of Veterinary Medicine. The experimental work involved subchronic exposure of three groups of 148 Japanese medaka fish (rice-fish minnows) to different aqueous concentrations of radon gas at LLNL. The purpose of the study was to examine effects of alpha exposure (arising from the decay of radon, which partitions into fish livers at a concentration proportional to that of radon in tank water) on the occurrence and growth of premalignant cells (namely, enzymatically altered proliferative "foci") in the livers of young fish exposed subchronically to different concentrations of radon gas. A separate experiment measured the tissue:water partition coefficient for radon between medaka soft tissue and surrounding tank water. Examination of fish livers from the primary study are currently being completed at U.C. Davis. 
Detailed descriptions of the three efforts summarized above are provided in Sections 2, 3 and 4 of this report, respectively, which follow. Each section is divided into background, methods, results and (where applicable) discussion subsections. Overall conclusions of this project are discussed in Section 5.

\section{Investigation of a Mechanistic Model Relating Radon Exposure to Lung-Cancer Risk Reflected in Combined Occupational and U.S. Residential Data}

\subsection{Background}

Lung cancer mortality (LCM) risk from residential radon exposure is generally estimated by linear-no-threshold extrapolation from data on LCM in miners, and currently is thought to pose the greatest indoor air-pollution threat in the U.S., causing $\sim 10 \%$ of all lung cancer and $\sim 20-30 \%$ of all lung cancer in nonsmokers (NRC, 1988,1998; Puskin, 1992). In contrast, ecologic data on county-level U.S. residential radon exposures appear negatively associated with corresponding ageadjusted LCM rates in male or female U.S. smokers+nonsmokers during the 1980s, inconsistent with linear-no-threshold predictions (Cohen, 1995,1997). The observed negative association, however, is based on analyses of ecologic (in this case, countylevel rather than individual-level) data, which are subject to unavoidable potential biases (Morgenstern, 1982; Piantadosi, 1994; Piantadosi et al., 1988), such as withincounty confounding due to smoking and age (Lubin, 1998; Smith et al., 1998).

In view of controversy regarding lung cancer risks posed by residential radon exposure, it is interesting that Cohen's negative association at residential exposure 
levels, and elevated LCM in miners, were jointly predicted by a mechanistic "cytodynamic 2-stage" (CD2) model of lung cancer using biologically plausible parameter estimates (Bogen, 1997). The CD2 fit obtained also happened to predict "inverse dose-rate" effects seen in miners, i.e., the greater risks observed in miners exposed over longer durations conditional on any given level of cumulative exposure (see (Lubin et al., 1994,1995a). The CD2 model realistically assumes linearno-threshold dose-response relations for alpha-induced cell killing and critical mutations (Bogen, 1997). Previous 2-stage stochastic "MVK"-model applications to radon presumed that premalignant-cell growth increases monotonically with cytotoxic radon dose (Luebeck et al., 1996; Moolgavkar et al., 1993). In contrast, the CD2 model may reflect net cytotoxic loss induced in exposed premalignant as well as exposed normal cells, and thus predict reduced cancer risk whenever: (i) induced cytotoxicity is sufficient to negate a slight net proliferative advantage presumed for spontaneous premalignant clones, but (ii) induced mutations yield too few new premalignant clones to offset the latter effect on tumor likelihood.

Although biologically plausible, the previous CD2 modeling results (Bogen, 1997) relied entirely on Cohen's ecologic LCM and radon-exposure data, as well as on summary (rather than individual-level) data on LCM in Colorado Plateau uranium miners in specified ranges of cumulative occupational radon exposure (NRC, 1988). The previous $\mathrm{CD} 2$ study was also limited by its focus on lifetime rather than agespecific LCM risk (since different patterns of age-specific risk over time can yield the same pattern of lifetime risk as a function of dose), and by the fact that a parameter governing alpha cytotoxic potency was estimated rather than fixed at a likely value. 
In the present study, each of these limitations was addressed by refitting the CD2 model, conditional on likely alpha cytotoxicity, to age-specific LCM data for white females of age $40+y$ in 2,821 U.S. counties during 1950-54 ( $90 \%$ of whom never smoked). Entirely new estimates of county-specific mean residential radon levels were used, together with age-specific LCM data obtained for five cohorts of underground miners who never smoked. The "inverse dose-rate" effect predicted by the new $\mathrm{CD} 2$ fit was also compared to LCM vs. dose-rate data pertaining to these miners. The partly ecologic design of this study (discussed below) did not remove any of the fundamental limitations posed by ecologic data use (noted above). Rather, this study was intended to better address the biological plausibility of apparent nonlinearity in dose-response for radon-induced lung cancer.

\subsection{Materials and Methods}

Residential Mortality and Smoking Data. Age- and county-specific 1950-54 LCM rates were obtained for U.S. white females (WF) aged 0-4, 5-9, .., 85+ y, excluding data for Virginia considered unreliable at the county level for that period (Marsh et al., 1996). Analyses excluded data on women $<40 \mathrm{y}$ for whom LCM was quite rare. Only $\sim 11 \%$ (vs. $\sim 5 \%$ ) of WF who died at $40+$ (vs. $60+$ ) y in $1950-54$ ever smoked, based on survey data covering this period (Haenszel and Shimkin, 1956; Mills and Porter, 1953). WF data were modeled for age $<80 \mathrm{y}$ only because the general pattern of LCM increase (a nearly cubic function of age) did not hold for older women. Such an apparent mortality-rate decline among the oldest age groups, which pertains to many types of cancer (Armitage and Doll, 1957), may be due to data unreliability (Doll and Peto, 1981) and/or population heterogeneity in cancer susceptibility, 
neither of which are addressed by the CD2 model.

Rn-Exposure, Socioeconomic and Climatic Data for U.S. Counties. In addition to VA data noted above, data for major retirement states (AZ, CA, FL) were dropped in view of survey data indicating a large fraction of lifetime spent near residence at time of death in non-retirement states (Cohen, 1992b), expected even more so for WF dying in 1950-54. New estimates of annual-average household radon concentrations for the remaining 2,821 U.S. counties were used, based on $\sim 4,700$ annual-average (long-term) and $\sim 50,000$ 3-day (short-term) radon U.S. Environmental Protection Agency national random-survey data. To obtain the new estimates, the latter survey data were systematically adjusted and interpolated to non-sampled counties using Monte-Carlo and regression methods, which incorporated county-level data on climatic and geophysical variates known to correlate with residential radon levels (Price, 1997; Price et al., 1998). The geometric mean levels were scaled uniformly to corresponding arithmetic means, assuming lognormal intra-county distributions with a common approximate geometric standard deviation of 2 (Cohen, 1992a; Price, 1999; Price, 1997).

Among the resulting new county-level estimates of household radon, 1,683 pertain to counties for which corresponding estimates were made previously using ad hoc methods to combine survey data obtained from multiple sources (Cohen, 1995). The latter and former estimates are fairly well correlated: $R^{2}=0.733$. For residential exposures, $1 \mathrm{pCi} /$ liter $(=0.037 \mathrm{~Bq})$ of radon in air was assumed to correspond to an annual exposure to 0.1935 "working level months" (WLM) of effective alpha energy (Puskin, 1992). 
Additionally, 12 types of 1950 demographic/socioeconomic data (USBC, 1953), 5 typical 1953-1975 climatic measures (Apte et al., 1997), weighted mean county elevation using census-tract populations as weights, and county-centroid latitude were each binned into county quintiles and were, together with a 3-level dietary Se index (Clark et al., 1991) and U.S. region (among 9), included in pairs as factors used in addition to age (within 10-y bins) in preliminary analyses of adjusted trend. Significant and generally similar negative (ecologic) trends for LCM vs. radon were obtained for all 210 sets of the 22 adjustment factors used (see Results). Therefore, for modeling purposes, county-level age-specific LCM data were adjusted by one representative factor (family-income quintile) and then pooled within 6 ranges of estimated annual average household radon exposure (corresponding to median radon concentrations of $<0.394,0.394-0.787,0.787-1.38,1.38-2.17,2.17-3.15$, and $>3.15$ $\mathrm{pCi} / \mathrm{L})$.

Occupational Data. Information from 5 of 6 cohorts for which data on LCM in nonsmoking underground miners are available (Lubin et al., 1994,1995a; NRC, 1998) was kindly provided by Dr. J. Lubin and coworkers. These person-year (PY) data ( $n=$ 2,488, 44,600.7 PY, 53 cases) were summarized by total LCM, PY and corresponding PY-weighted median values of attained age in y (AGE), age at first exposure in $y$ $\left(\mathrm{AGE}_{0}\right)$, calendar year of follow-up (YR), exposure duration in y excluding the $5 \mathrm{y}$ prior to attained age (DUR), and cumulative exposure in WLM up to $5 \mathrm{y}$ prior to attained age (WLM), for the five WLM bins and three attained-age bins used by Lubin et al., (1994, pp. 84-5), and for DUR ranges of 0-7, 8-15, and $\geq 16 \mathrm{y}$.

Cancer Risk Model. The CD2 model (Figure 1) was used with the changes 


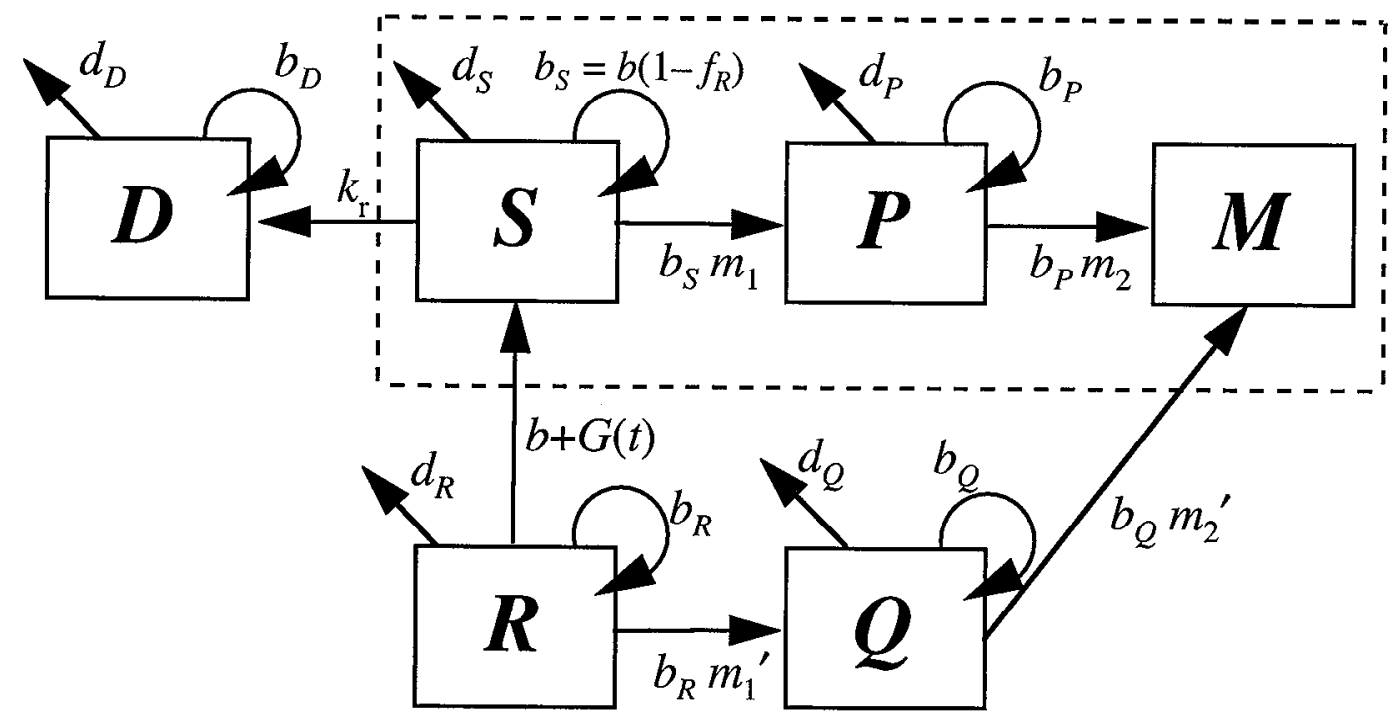

Figure 1. Cytodynamic 2-stage (CD2) model of bronchial carcinogenesis (Bogen, 1997), in corporating the "MVK" stochastic 2-stage fram ework (dashed box; see Moolgavkar, 1983) whereby normal epithelial stem cells (S) may each with probability $m_{1}$ per cell division give rise to a premalignant cell $(P)$, which may proliferate clonally and with probability $m_{2}$ give rise to a malignant cell $(M)$. The CD2 model adds a reservoir of unexposed cells $(R)$ that may play a alpha-enhanced role in replacing $S$-cells lost at rate $k_{\mathrm{r}}$ to become reproductively dead cells $(D)$. $R$-cells may progress to premalignant $(Q)$ and malignant $(M)$ cells via a process parallel to yet independent from the $S \rightarrow P \rightarrow M$ process. Rates of birth $(b)$ and death/differentiation $(d)$ are specified for each cell type, $f_{\mathrm{R}}$ is the ratio $R / S$ under normal conditions. 
noted. This model adapts the "MVK" 2-stage mechanistic framework, in which transition of normal $(S)$ to premalignant $(P)$ cells and of $P \sim$ cells to malignant cells $(M)$ is modeled as a doubly stochastic filtered Poisson process (Moolgavkar, 1983; Moolgavkar et al., 1993). As applied to radon, the CD2 model additionally assumes: (i) alpha-induced transition from $S$ to a pool of reproductively dead cells $(D)$, (ii) replacement of $S$-cells partly by virtually unexposed cells $(R)$ via a Verhulst feedback-inhibition process (where $f_{R}$ denotes the ratio $R / S$ under noncytotoxic conditions), and (iii) similarly unexposed premalignant $(Q)$ cells derived from $R$ cells and subject to malignant transformation via a process similar to and independent from the $S \rightarrow P \rightarrow M$ process. Mathematical details are given in the Appendix. In terms of notation and relations previously described (Bogen, 1997), new assumptions used for the present study were: (1) dose rate $(E)$ in cGy $\mathrm{y}^{-1}$ to surface (secretory) cells in lobar/segmental bronchi was estimated to be 3.3 and 4.4 cGy $\mathrm{WLM}^{-1}$ for residents and miners, respectively (NRC, 1991); (2) excess relative risk was modeled as $s \times E$ (unitless) for $S \rightarrow P$ and $P \rightarrow M$ transitions; (3) $k_{\mathrm{r}}$ was modeled as $E / D_{0}$ with $D_{0}$ taken to be the inverse-variance-weighted mean ( $35 \mathrm{cGy}$ ) of published $D_{0}$ values for alpha-induced killing of human lung cells in vitro (Raju et al., 1993; Simmons et al., 1996); (4) $d_{Q}$ was modeled as $b_{Q}-g\left[1+c\left(b_{R} b^{-1}-1\right)\right]$; (5) $R \rightarrow Q$ and $Q \rightarrow M$ transitions were presumed to occur at a background rate per cell division of $w \times m$ (vs. the rate $m$ assumed for $S \rightarrow P$ and $P \rightarrow M$ transitions); and (6) the target-cell turnover rate $b$ was assumed to have the plausible value $4 \mathrm{y}^{-1}$ (Bogen, 1997). Other CD2 parameters were assigned biologically plausible values previously used (Bogen, 
1997) (see Appendix 1 at the end of this report).

Data Analysis. The CD2 model with 6 estimated parameters $\left(m, w, f_{R}, g, c\right.$, and s) described was fit to $8 \times 6=48$ income-adjusted age- and exposure-specific residential LCM rates, plus $3 \times 5=15$ age- and WLM-bin-specific occupational LCM rates, assuming corresponding Poisson errors that were estimated by standard methods (Chiang, 1984). This model was evaluated analytically (see Appendix 1), and parameter and corresponding standard error (SE) values were obtained by inverse-variance weighted chi-square minimization (Press et al., 1992) (i.e., by a method that is approximately maximum-likelihood, particularly with respect to residential LCM rates based on so many cases that assumed Poisson errors were virtually Gaussian). Outlying data were assessed by corresponding (approximate) Ftests.

The resulting fit was also compared graphically (i.e., and not fit) to estimates and $95 \%$ confidence-limit (CL) values for: (i) relative risk (RR) of LCM adjusted for age and income in residential WF, based on U.S. county-level mortality data discussed above; (ii) age-adjusted RR of LCM in residential WF as predicted by "preferred" BEIR VI risk-extrapolation models (NRC, 1998), (iii) RR of LCM reported by Lubin et al. (1994, p.88) as a function of WLM in 6 cohorts of never-smoking underground miners adjusted for age, cohort, and previous occupational exposures; and (iv) RR of LCM in 5 of the latter miner cohorts (using data discussed above) adjusted for AGE and YR, as three functions of DUR corresponding to the WLM ranges: $\leq 400,>400-800$, and $>800-1600$ WLM. The latter comparison involved RRs estimated de novo from data on 5 of 6 miner cohorts because previous studies 
(Lubin et al., 1995a; Lubin et al., 1994; NRC, 1998) did not examine RR as a function of DUR for miners who never smoked. A $>1600$-WLM exposure category was not included in this comparison because CLs on the estimated (elevated) RRs were too large for a comparison to $\mathrm{CD} 2$ predictions to be meaningful.

For the graphical comparisons described, internally standardized RR implied by the $\mathrm{CD} 2$ fit (or predicted by BEIR VI models) were defined as the corresponding weighted mean of predicted age-specific RRs, using LCM numerators (i.e., inverse coefficients of variation) of age-specific 1950-54 rates of WF LCM as common agespecific weights. Comparisons between the occupational data and corresponding CD2 model predictions for LCM as functions of (i) WLM and (ii) DUR also made use of the corresponding assumptions: (i) DUR $=9.62[1-\exp (-0.00358 \times W L M)]$ (nonlinear least-squares fit to the 15 data subsets, $\left.\mathrm{R}^{2}=0.808\right)$, and (ii) $\left(\mathrm{AGE}_{0} / \mathrm{AGE}\right)=$ $0.708-0.0122 \times$ DUR (linear least-squares fit to 27 similar subsets of the occupational data classified within three ranges of AGE, DUR and WLM cited above $\left(R^{2}=0.812, p\right.$ $\left.=1.5 \times 10^{-10}\right)$. Numerical maximum-likelihood methods were used to obtain all $\mathrm{RR}$ and CL values, as well as to obtain adjusted chi-square values for trend in the trend analyses mentioned above (Breslow and Day, 1987a). Also used in trend analyses were standardized relative-risk slopes, each defined as (adjusted LCM slope)/(unadjusted LCM intercept), with the latter slope and intercept estimated using standard methods (Fleiss, 1981). All calculations were performed using Mathematica $3.0^{\circledR}$ software (Wolfram, 1996). 


\subsection{Results}

A separate analysis (summarized in Appendix 2) addressed potential effects of predicted intra-county variation in radon concentration on the likelihood of misclassification pertaining to the six nominal ranges of estimated annual average household radon exposure (corresponding to median radon concentrations of $<0.394,0.394-0.787,0.787-1.38,1.38-2.17,2.17-3.15$, and $>3.15 \mathrm{pCi} / \mathrm{L}$ ) that were used for the present study. This analysis showed that, despite considerable predicted intracounty variability in radon concentration, only $\sim 1 \%$ and $\sim 5 \%$ of houses in lowest and 2nd lowest radon bins, respectively, are predicted to have been misclassified from the highest 2 bins; and only $\sim 2 \%$ and $\sim 7 \%$ of houses in highest and 2 nd highest radon bins, respectively, are predicted to have been misclassified from the lowest 2 bins (Price, 1999).

Table 1 summarizes results obtained from a trend analysis of LCM vs. radonconcentration bin adjusted for age and one among 21 factors considered indicate a consistent, significantly negative association between radon level and LCM, for all women as well as older women. This was also found in a similar analysis of trend adjusted for age and 210 combinations of two among the 21 other county-level factors considered, summarized in Figure 2. From the latter analysis, the median (and upper 2-tailed 95\% CL) of p-values for (negative) trend obtained was $7.5 \times 10^{-9}$ $(0.0032)$ for all women $(40+y)$ and $4.5 \times 10^{-7}(0.0052)$ for older women $(60+y)$. The corresponding median (and 95\% CL) of relative-risk slopes was found to be -1.6 $(-0.84,-2.2) \mathrm{L} \mathrm{Bq}^{-1}$ for all women $(40+\mathrm{y})$, vs. $-1.5(-0.92,-2.1) \mathrm{L} \mathrm{Bq}^{-1}$ for older women $(60+y)$. Thus, statistically significant and generally similar negative (ecologic) trends 
Table 1. Trend in the relative risk (RR) of lung cancer mortality (LCM) among women in U.S. counties from 1950-54 as a function of county mean residential radon level, adjusted for various factors.*

\begin{tabular}{|c|c|c|c|c|c|c|}
\hline \multirow[b]{2}{*}{$\begin{array}{l}\text { Adjusted for } \\
\text { age, and }\end{array}$} & \multicolumn{3}{|c|}{ Age $\geq 40 y$} & \multicolumn{3}{|c|}{ Age $\geq 60 y$} \\
\hline & $\begin{array}{c}\text { RR Slope }^{\star \star} \\
\times(-100) \\
\end{array}$ & $\begin{array}{l}\mathrm{CV}^{* \star} \\
( \pm \%)\end{array}$ & $\begin{array}{l}-\log _{10} p \\
\text { for } \chi_{\text {trend }}^{2}\end{array}$ & $\begin{array}{l}\text { RR Slope } e^{* *} \\
\times(-100) \\
\end{array}$ & $\begin{array}{l}\mathrm{CV}^{* *} \\
( \pm \%)\end{array}$ & $\begin{array}{l}-\log _{10} p \\
\text { for } \chi_{\text {trend }}^{2}\end{array}$ \\
\hline Age only & 7.5 & 26 & 15. & 7.2 & 25 & 11. \\
\hline Agr. work & 6.5 & 21 & 11. & 8.1 & 19 & 11. \\
\hline Density & 6.6 & 21 & 12. & 6.2 & 21 & 8.4 \\
\hline Elevation $_{\mathrm{pw}}$ & 3.3 & 44 & 2.8 & 3.9 & 37 & 3.1 \\
\hline Fem. work & 6.8 & 21 & 13. & 6.4 & 21 & 8.8 \\
\hline Heating IDD & 5.8 & 26 & 8.1 & 6.6 & 21 & 9.4 \\
\hline High school & 8.3 & 18 & $>16$ & 5.9 & 25 & 6.5 \\
\hline Income & 7.3 & 21 & 14. & 7.7 & 18 & 12. \\
\hline Latitude & 7.9 & 21 & 15. & 7.6 & 20 & 11. \\
\hline Migration & 6.2 & 24 & 10. & 6.8 & 21 & 9.6 \\
\hline Poor & 7.5 & 19 & 15. & 6.2 & 24 & 8.2 \\
\hline Precip.-h & 8.4 & 18 & $>16$ & 7.0 & 20 & 10. \\
\hline Region & 8.3 & 19 & 15. & 7.9 & 19 & 13. \\
\hline Rich & 6.9 & 20 & 13. & 6.5 & 20 & 8.8 \\
\hline Rural & 6.6 & 20 & 12. & 6.5 & 20 & 9.0 \\
\hline School & 8.1 & 19 & $>16$ & 7.7 & 19 & 12. \\
\hline Selenium & 5.2 & 28 & 7.8 & 5.2 & 28 & 5.9 \\
\hline Temp. Jan & 5.2 & 32 & 6.2 & 5.0 & 33 & 4.6 \\
\hline Temp. Jul & 7.3 & 19 & 13. & 7.0 & 19 & 9.4 \\
\hline Uneduc. & 5.1 & 31 & 6.3 & 4.9 & 32 & 4.6 \\
\hline Urban & 6.5 & 21 & 12. & 6.2 & 20 & 8.5 \\
\hline Wind & 8.0 & 18 & $>16$ & 7.6 & 18 & 12. \\
\hline
\end{tabular}




\section{Footnotes for Table 1}

${ }^{*}$ LCM was compared among 6 groups of counties classified by mean residential radon level (RL), after adjusting for age and the listed factors, which were classified into U.S.-county quintiles, except as otherwise noted. Agric. work $=\%$ employed in agriculture, Density $=$ population density $\left(\# \mathrm{~km}^{-2}\right)$, Elevation ${ }_{\mathrm{pw}}=$ populationweighted elevation $(\mathrm{m})$, Fem. work $=\%$ females in total labor force, Heating IDD = heating infiltration degree-days $\left({ }^{\circ} \mathrm{F}-\mathrm{d}\right)$, High school $=\%$ completed high school or more, Income $=$ median family income $(\$)$, Migration $=\#$ persons living in a different county or abroad in 1945 vs. 1950, Poor $=\%$ with income $<\$ 2000$, Precip. $-\mathrm{h}=$ mean precipitation $\left(\mathrm{h} \mathrm{d}^{-1}\right)$, Region = location among 9 U.S. divisions, Rich $=\%$ with income $>\$ 5000$, Rural/Urban $=\%$ rural-farm/urban population, School $=$ median schooling completed $(y)$, Selenium $=$ index $(0,1$, or 2$)$ of relative exposure to dietary selenium based on foliage Se content, Temp. Jan/Jul = mean daily temperature for $\mathrm{Jan} / \mathrm{Jul}\left({ }^{\circ} \mathrm{F}\right)$, Uneducated $=\%$ who completed grade $<5$, Wind $=$ mean daily wind speed $\left(\mathrm{m} \mathrm{s}^{-1}\right)$.

**The standardized RR slope $\left(\mathrm{B}_{\text {adj }}\right)$ was calculated as $\mathrm{B}_{\mathrm{adj}}=b_{\mathrm{adj}} / a$, where $b_{\mathrm{adj}}=$ the adjusted slope for linear LCM trend, and $a=$ the unadjusted LCM intercept; CV = $100 \% \times\left(\right.$ standard deviation of $\left.B_{a d j}\right) / B_{\text {adj }}$. 

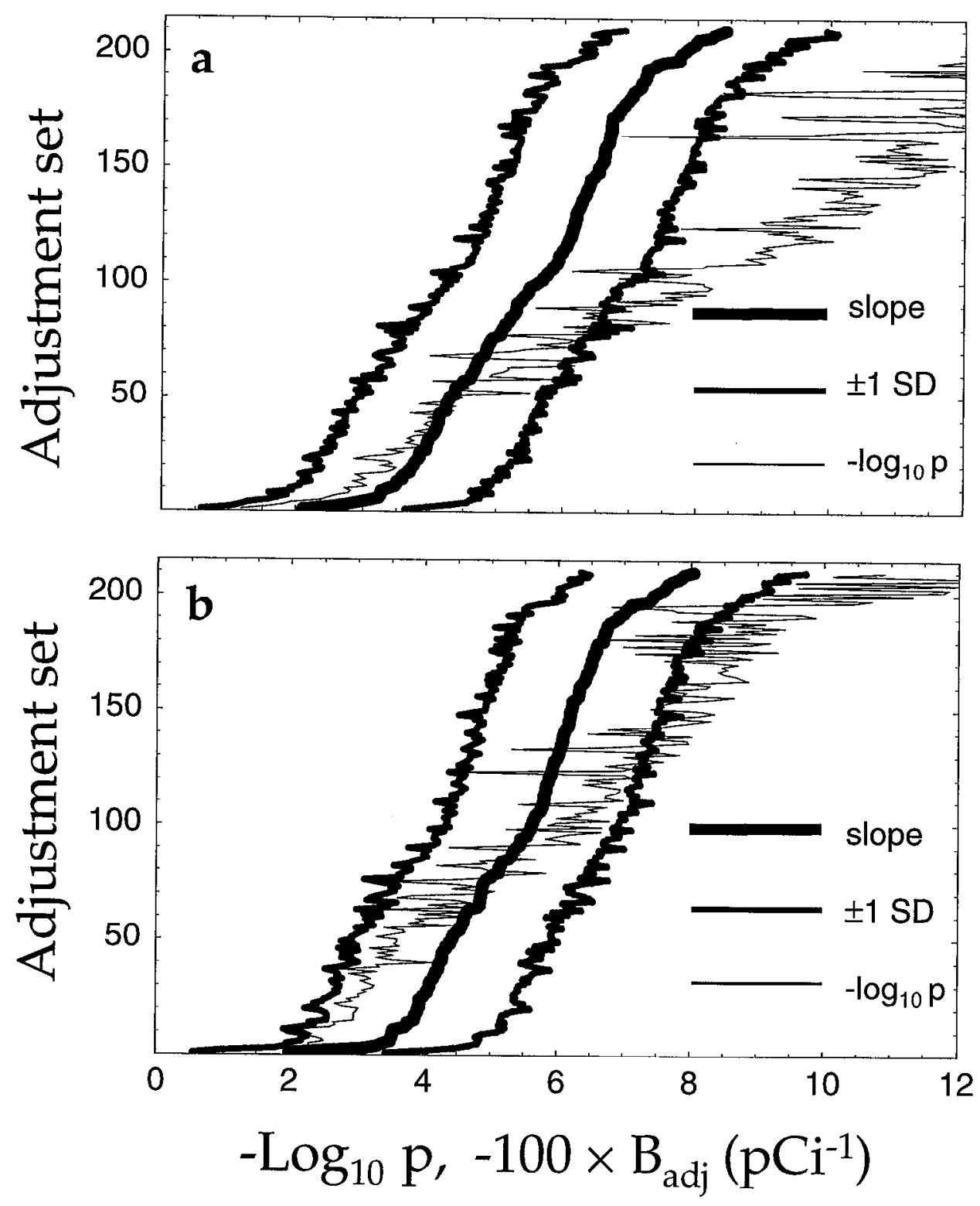

Figure 2. Adjusted relative-risk slopes and corresponding p-values for adjusted trend in 210 analyses adjusting for age and two additional variates (am ong those listed in Table 1) are shown for U.S. females (a) 40+, and (b) 60+, years of age. Cumulative distributions of normalized adjusted slope $\left(B_{\text {adj }}\right)$ are surrounded by corresponding lower and upper ( $\pm 1 \mathrm{SD}$ ) bounds; corresponding $\mathrm{p}$-values plotted as $\left(-\log _{10} \mathrm{p}\right)^{-1}$ for corresponding adjusted tests of trend are overlaid. Slope values refer to linear trend in relative-risk of lung cancer mortality (LCM) in U.S. fem ales during 1950-54, for county data pooled with in 6 ranges of estimated annual average household radon exposure, with slope calculated as $\mathrm{B}_{\text {adj }}=b_{\text {adj }} / a$ where $b_{\text {adj }}=$ the adjusted LCM slope and $a=$ the unadjusted LCM intercept. 
for LCM vs. radon were observed using either data on all women $(40+y)$ or data pertaining only to older women $(60+y)$.

An adequate CD2 fit was obtained to the combined $(n=63)$ age-specific residential $/$ miner LCM data $\left(\chi^{2}=73.8, \mathrm{df}=57, \mathrm{p}=0.066\right)$, which was improved significantly $\left(\mathrm{F}_{2,55}=9.72, \mathrm{p}=0.00024\right)$ by dropping one outlying data point from each data subset $\left(\chi^{2}=54.6, \mathrm{df}=55, \mathrm{p}=0.49\right)$. Parameter estimates $( \pm 100 \% \times \mathrm{SE} /$ estimate $)$ corresponding to the latter $\mathrm{CD} 2$ fit were: $m b=0.76 \times 10^{-8} \mathrm{y}^{-1}( \pm 12 \%), w=3.7( \pm 27 \%)$, $f_{R}=0.063( \pm 50 \%), g=0.0893 \mathrm{y}^{-1}( \pm 4.9 \%), c=0.35( \pm 65 \%)$, and $s=0.11 \mathrm{y} \mathrm{cGy}^{-1}( \pm 160 \%)$. Figure 3 shows the corresponding CD2 fit obtained to income-adjusted age-specific data on LCM in U.S. WF in 1950-54 for two of the six county-mean household radon levels considered. RR values predicted by this CD2 fit under residential-exposure assumptions are compared in Figure 4a to: (i) corresponding RR estimates that summarize LCM in U.S. WF in 1950-54 as a function of county-mean residential radon level, and (ii) corresponding RR values predicted by "preferred" BEIR VI models (NRC, 1998). Figure $4 \mathrm{~b}$ shows how, under mining-exposure assumptions reflecting the actual experience of nonsmoking miners, the CD2-model predicts RRs consistent with those summarizing the age-specific miner data used. Figure 5 shows how, under similar assumptions concerning nonsmoking miners, the CD2-model predicts RRs consistent with "inverse dose-rate" effects on RR apparent in miners, even though the model was not fit to any data concerning inverse dose-rate effects.

\subsection{Discussion}

The similarity in trend-analysis results obtained using age-specific 1950-54 data 


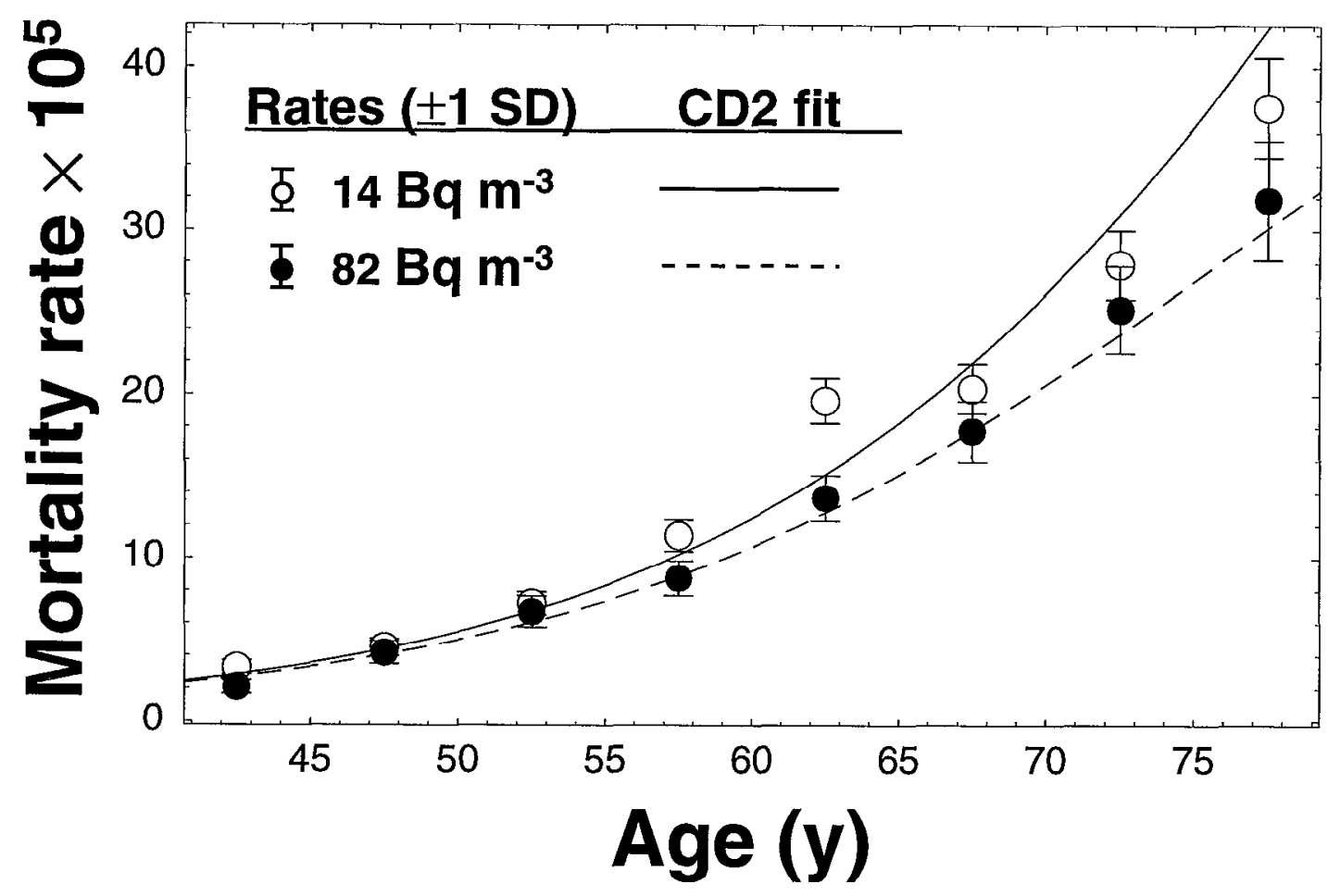

Figure 3. Age-specific rates of lung cancer mortality (LCM) in U.S. white fem ales during 1950-54 adjusted for income, pertaining to counties with in 2 different ranges of county-mean residential radon concentration. The LCM data are com pared to age-specific LCM rates predicted by the 6-parameter CD2 model fit jointly to: (i) the data points shown, (ii) similar U.S. county-level data for 4 other ranges of county-mean residential radon, and (iii) age-specific LCM rates for a total of 2,488 miners who never smoked (goodness of fit to combined data: $\chi^{2}=54.6, \mathrm{df}=55, \mathrm{p}=0.49$ ). 

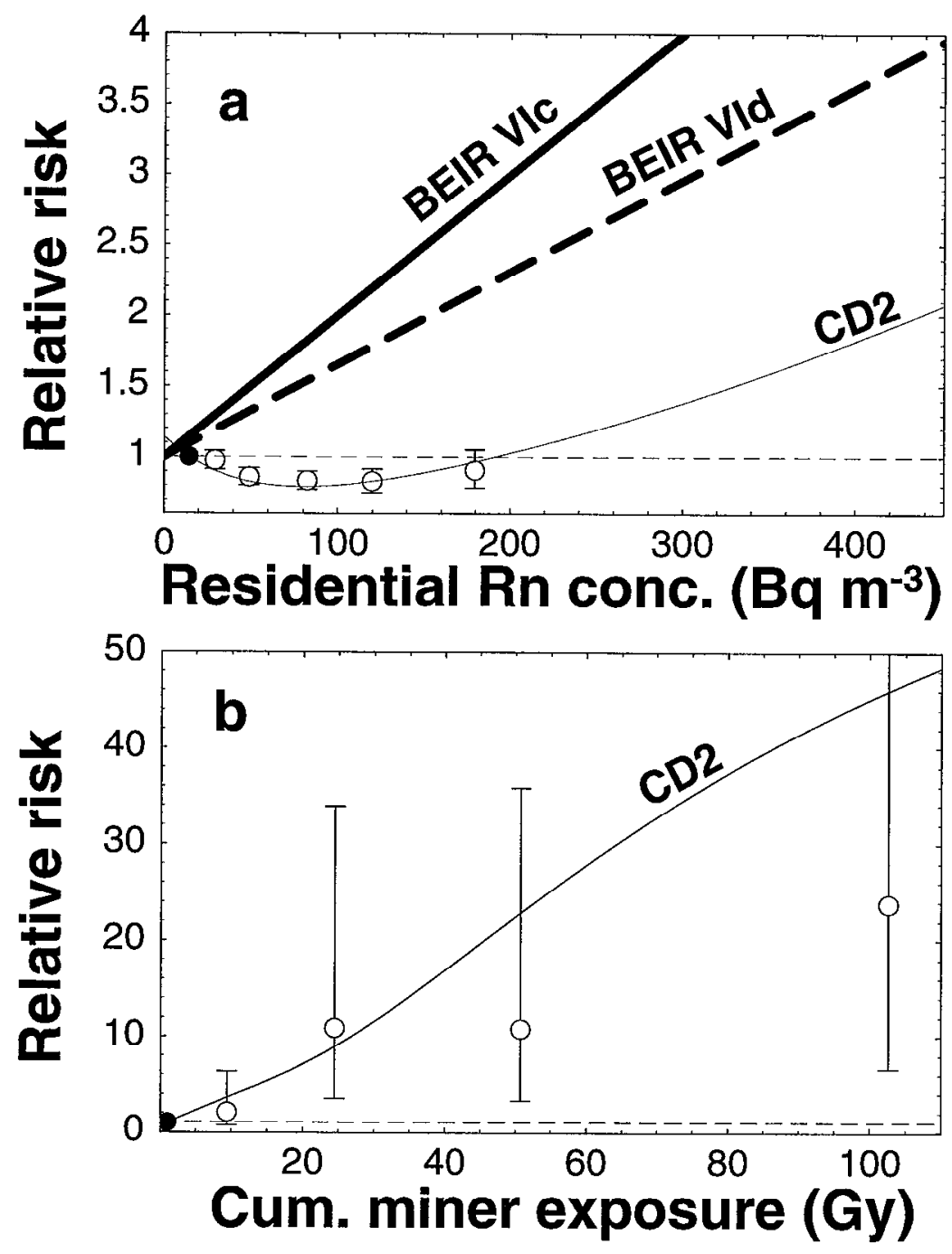

Figure 4. Relative risk (RR) of increased lung cancer mortality (LCM) in (a) U.S. white females (WF) during 1950-54, adjusted for age and income, vs. county-mean residential radon concentration within 6 ranges; and (b) 2,488 nonsmoking underground miners adjusted for age, cohort, and previous occupational exposures, vs. cumulative underground mining exposure as reported by Lubin et al. (1994). Each set of RR estimates was based on internal comparisons to data (solid points) corresponding to the lowest exposure group ( $R R=1$, dashed line), and is compared to RRs predicted by the 6param eter CD2 model fit to 61 age-specific LCM rates for WF and nonsm oking miners (see Figure 3) correspon ding to the RR estimates shown. Plot (a) also shows RR for female nonsmokers predicted by the "preferred" (12- and 13parameter) BEIR VI linear-extrapolation models: BEIR VIc $=$ age-exposureconcentration model, BEIR VId = age-exposure-duration model (NRC, 1998). 


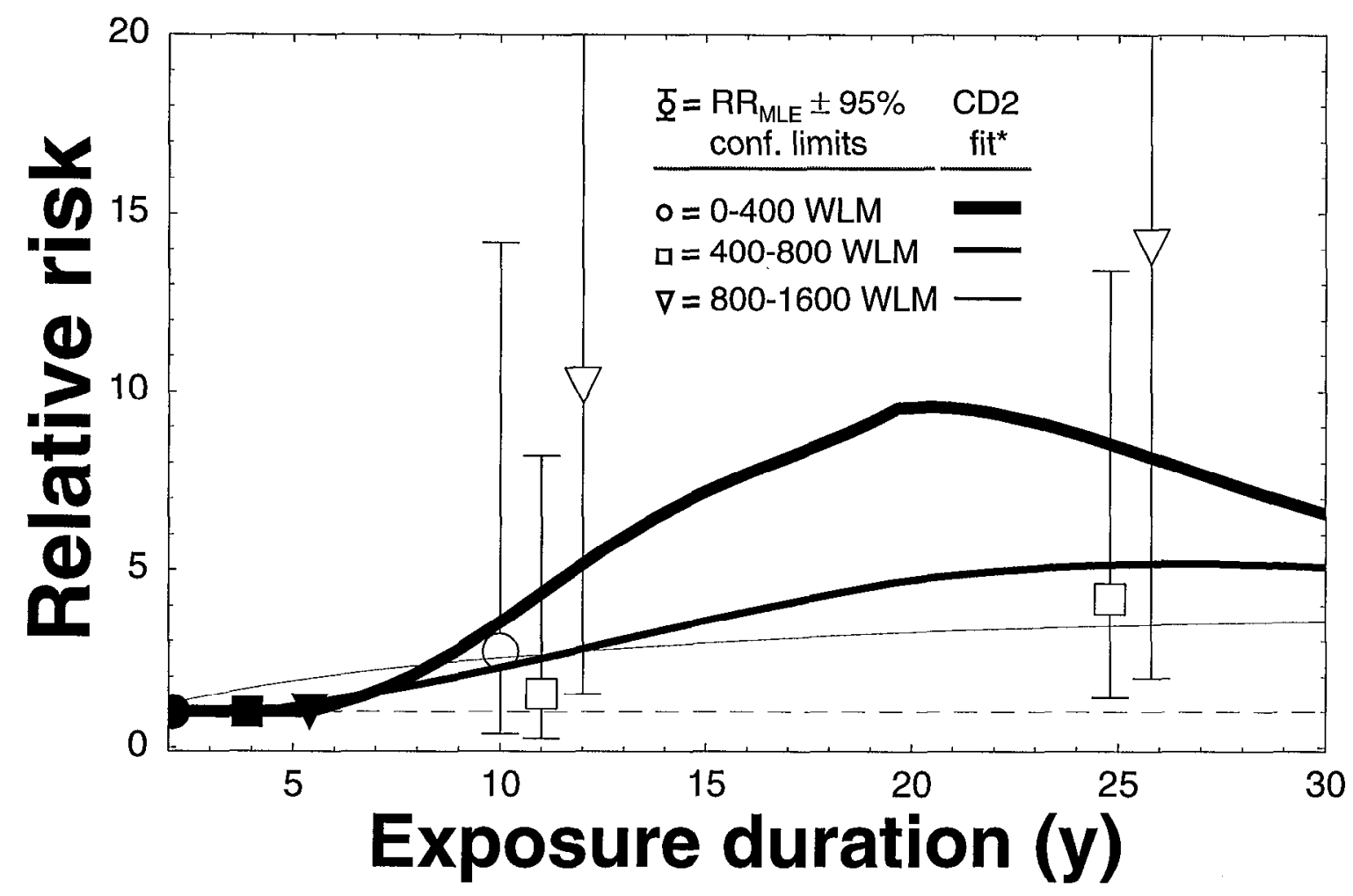

Figure 5. Relative risk (RR) of increased lung cancer mortality (LCM) adjusted for age and year of observation in nonsmoking underground miners within different categories of cumulative exposure, vs. mining-exposure duration; based on internal comparison to LCM in miners exposed for $<8 \mathrm{y}$ (solid points on dashed line indicating $R R=1$ ). The $R R$ estimates are compared to values predicted by the 6-parameter CD2 model fit-not to the data points shown here-but rather to 61 age-specific LCM rates for 1950-54 WF and nonsmoking miners (see Figure 2). 
on Lcm in U.S. women of age $40+$ vs. $60+$, despite far less smoking among the older women, indicates that inter-county confounding by smoking is unlikely to explain the apparent negative trend in age-specific data on LCM vs. residential radon. As noted (Introduction), these negative trends may be due entirely or in part to a confounding artifact due to within-county correlations unaffected by the various county-level adjustments made in this study (Lubin, 1998; Pershagen, 1998; Smith et al., 1998). The results above indicate, however, that these negative trends are also consistent with a biologically realistic six-parameter CD2 model that also predicts high-dose as well as dose-rate effects in miners. In particular, CD2 estimates obtained for $b m$ and $b m w\left(\sim 10^{-8} \mathrm{y}^{-1}\right)$ are consistent with in vivo somatic hpgrt-genemutation rates estimated for human T-lymphocytes, which in turn have been used to estimate somatic human-oncogene mutation rates (King et al., 1994; Mendelsohn, 1990; Robinson et al., 1994; Trainor et al., 1984). The CD2 estimate for $f_{R}(\sim 6 \%)$ is consistent with relevant histological and microdosimetric variabilities, and/or with a possible source of unexposed bronchial-epithelium stem cells within underlying submucosal-gland ciliated ducts-see the detailed discussion and references cited in Appendix 1 of Bogen (1997).

In conclusion, the results of this study support the biological plausibility of the hypothesis long argued by Cohen (Cohen, 1995), that LCM is not increased by exposure to radon at residential levels. More specifically, they are consistent with a mechanistically based U-shaped (or "hormetic") dose-response pattern for radon's effect on lung-cancer risk, but by no means prove that this pattern either is the case or is as large as suggested by the U.S. ecologic data considered. The U-shaped CD2 fit 
obtained in this study differs sharply from linear-no-threshold models, such as the 12- or 13-parameter "BEIR VI" (NRC, 1998) models currently used to extrapolate lung-cancer risks for low-level radon exposures (Figure 4). The present study thus indicates that some consideration of fundamental model uncertainty ought to play a role in risk management for residential radon (Bogen and Layton, 1998).

Furthermore, the results obtained pose testable mechanistic hypotheses concerning the effect of subchronic or chronic exposure to relatively cytotoxic genotoxins, such as alpha radiation, on growth kinetics of premalignant foci. After chronic administration of chemical carcinogens, development of focal cytotoxic resistance in proliferative foci has been attributed to clonal selection for mutations that decrease chemical uptake, decrease metabolic activation, increase deactivation, increase excretion, increase DNA repair, etc. (Emmelot and Scherer, 1980; Last et al., 1987). Even so, chronic chemical carcinogen exposures have been shown to reduce tumor yields significantly under some conditions (Kociba, 1978; Witschi et al., 1997). In the case of radon, one underlying CD2 hypothesis is that premalignant foci are no more resistant than surrounding normal cells to chronic alpha-induced cell death. Focal resistance is not expected in the case of alpha radiation, because a fraction of the damage (e.g., multiple chromosome breaks) induced is predictably misrepaired to states that are at least reproductively lethal.

Another key CD2 hypothesis is that cell proliferation induced to compensate for normal-cell loss from low-level alpha exposure is not accompanied by the same amount of (or any) increased proliferation in surface-epithelial ( $P$-cell) premalignant foci. At low levels of induced target-cell killing, the CD2 model used posits that: (i) 
this low level of chronic cell killing is too low to induce fully compensatory cell proliferation, and/or (ii) focal cells (already assumed to have an elevated rate of proliferation-see Appendix) are either less responsive or totally unresponsive to mitogenic signals that induce regenerative proliferation in surrounding normal cells. The second of these assumptions is supported by the observation that magnitudes of relatively increased mitotic rates in foci compared to normal rat liver cells are characteristic of particular focal types (Zerban et al., 1994). Experiments that address this issue directly, which have yet to be done, may thus provide data critical to improved risk prediction for low-level exposures to those carcinogens, like alpha radiation, expected to be similarly cytotoxic to both normal and premalignant cells.

Improved risk extrapolation for residential radon exposures will, of course, ultimately rely on large, well designed case-control and cohort studies. Previous non-ecologic epidemiological studies have yielded mixed results, generally consistent with low-dose linearity, but also insufficiently powerful and not well designed to test specific nonlinear hypotheses (Bogen, 1997; Lubin et al., 1995b; NRC, 1998; Samet, 1989; Stidley and Samet, 1993). Better predictions will require detailed exposure histories and lung-cancer data concerning tens of thousands of people (Lubin et al., 1995b). A coordinated effort to generate a database of large magnitude is now underway in Europe, Canada and the U.S. Initial results indicate a relativerisk pattern that is nearly linear for some data sets (e.g., those focusing on areas of relatively high residential exposure-(Darby et al., 1998; Pershagen, 1998)), but flat or possibly U-shaped for other data sets (e.g., those focusing on combined low and high residential-exposure areas, or on nonsmokers-(Alavanja et al., 1994; Létourneau et 
al., 1994; Pershagen, 1998; Wichmann et al., 1998)). The degree of nonlinearity predicted by the CD2 model is a sensitive function of the ratio of cytotoxic to mutagenic potencies assumed (Bogen, 1997). However, the key assumption behind this predicted nonlinearity-alpha-induced killing of premalignant cells in bronchial-surface epithelium - is highly likely. Some (albcit perhaps negligible) nonlinearity in lung-cancer risk due to residential radon is thus predicted by current, mechanistically based multistage cancer theory. If properly designed, future analyses of expanded sets of residential case-control data will bound the magnitude and significance of such nonlinearity. 


\section{Historical U.S. Residential Fuel Use and Female Lung Cancer Mortality}

[coauthored by J. Cullen and Dr. K.T. Bogen]

\subsection{Background}

U.S. female lung cancer mortality increased dramatically during the $20^{\text {th }}$ century. Cigarette smoking patterns, movement into industrial occupations and outdoor air pollution have been associated with this increase (Chen et al., 1992). However, despite early century female domestication, residential air pollution has not been thoroughly examined in relation to these historical mortality patterns.

Increasing attention has focused on the relation between residential fuel combustion and lung disease, particularly in China where cooking and heating with coal and wood is still a common practice (Band el al., 1990; Chapman el al., 1988; Chen el al., 1990; He et al., 1991; Liu et al., 1991,1993; Mumford et al., 1987,1989; Qing et al., 1993; Xu et al., 1986,1989), as summarized in Table 2. Ecological studies have shown exceptionally high female lung cancer mortality rates in Northern China despite an estimated $0.2 \%$ female smoking prevalence (Band et al., 1990; Chapman et al., 1988; Chen et al., 1992; He et al., 1991; Liu et al., 1991; Mumford et al., 1987,1989; Xu et al., 1989). Case-control studies have also shown a strong association between residential coal use and female lung cancer mortality in Northern China (Chen et al., 1990; Gao et al., 1987; Liu et al., 1993; Liu et al., 1989,1991). Other putative risk factors, such as passive smoking and occupation, do not account for the exceptionally high lung cancer mortality among these women (Band et al., 1990; Chapman et al., 1988; Mumford et al., 1987,1989). Historically, occupational studies of coal mining and lung cancer have been inconclusive, showing both elevated and reduced disease rates associated with mining (Ames et al., 1983; Armstrong et al., 1979; Bertrand et al., 1987; Chovil, 1979; Cockcroft and Andersson, 1987; Costello et al., 
Table 2. Association of residential coal use with increased lung cancer risk in chinese regions.

\begin{tabular}{|c|c|c|c|c|c|c|c|}
\hline $\begin{array}{l}\text { Study } \\
\text { design* }\end{array}$ & $\begin{array}{l}\text { Study size } \\
\text { (Cases/Contr.) }\end{array}$ & Exposure type & $\begin{array}{c}\text { Exposure } \\
\text { level }\end{array}$ & $\begin{array}{c}\text { Risk } \\
\text { measure* }\end{array}$ & Est. & $\begin{array}{l}\text { p value } \\
\text { (or } \mathrm{CI})^{*}\end{array}$ & Reference \\
\hline Ecol. & $\begin{array}{l}11 \\
\text { Communes }\end{array}$ & Smoky coal use (\%) & $\begin{array}{r}0 \% \\
50 \% \\
100 \%\end{array}$ & PRR & $\begin{array}{r}1.0 \\
15.4 \\
217\end{array}$ & NP & $\begin{array}{l}\text { Chen et al. } \\
1990\end{array}$ \\
\hline $\mathrm{CC}$ & $(1249 / 1345)$ & $\begin{array}{r}\text { Use vs. non-use }(\mathrm{y}) \text { of: } \\
\text { central gas } \\
\text { coal stove } \\
\text { open coal bed } \\
\text { coal bed }\end{array}$ & $\begin{array}{ll}30+\text { vs. } & 0 \\
50+\text { vs. } & 0 \\
20+\text { vs. } & 0 \\
50+\text { vs. } & 0\end{array}$ & $\mathrm{RR}_{\mathrm{adj}}$ & $\begin{array}{l}0.8 \\
1.2 \\
2.3 \\
3.4\end{array}$ & $\begin{array}{l}\text { NS } \\
\text { NS } \\
<0.05 \\
<0.05\end{array}$ & $\begin{array}{c}\text { Morabia et al. } \\
1992\end{array}$ \\
\hline $\mathrm{CC}$ & $(110 / 426)$ & Female cooking $(y)$ & $\begin{array}{r}30-44 \text { vs. }<30 \\
>44 \text { vs. }<30\end{array}$ & OR & $\begin{array}{l}7.23 \\
8.43\end{array}$ & $\begin{array}{l}<0.05 \\
\text { NS }\end{array}$ & $\begin{array}{l}\text { Wu-Williams } \\
\text { et al. } 1993\end{array}$ \\
\hline \multirow[t]{2}{*}{$\mathrm{CC}$} & $(139 / 139)$ & Smoky coal use & Yes/No & $\mathrm{OR}_{\mathrm{adj}}$ & 7.53 & $(3.31-17.2)$ & Xu et al. 1989 \\
\hline & & $\begin{array}{l}\text { Net tons smoky coal } \\
\text { used per y }\end{array}$ & $\begin{array}{ll}<3 \text { vs. } & 0 \\
>3 \text { vs. } & 0\end{array}$ & & $\begin{array}{l}8.24 \\
7.53\end{array}$ & $\begin{array}{c}(2.33-29.2) \\
(3.03-18.7) \\
<0.001 \text { (trend) }\end{array}$ & \\
\hline CS & $117,035 \mathrm{PY}$ & Males: Coal vs. gas use & - & $\begin{array}{l}\text { RR } \\
\text { SRR }\end{array}$ & $\begin{array}{l}1.44 \\
1.45 \\
\end{array}$ & $\begin{array}{l}\text { NP } \\
\text { NP }\end{array}$ & $\begin{array}{c}\text { Gao et al. } \\
1987\end{array}$ \\
\hline
\end{tabular}

${ }^{*} \mathrm{PRR}=$ prevalence rate ratio, $\mathrm{RR}=$ relative risk, $\mathrm{OR}=$ odds ratio, $\mathrm{CC}=$ case control, $\mathrm{CS}=$ cross-sectional, Ecol. = ecological, $L C M=$ lung cancer mortality. $R_{2} R_{a j}=R R$ adjusted for age, education, smoking; $\mathrm{OR}_{\mathrm{adj}}=\mathrm{OR}$ adjusted for age, menstrual-cycle duration, menopause, age, family chronic-bronchitis/LC history; CI-confidence interval. 
1974; Dalal et al., 1991; Gustavsson et al., 1988; IARC, 1997; Levin et al., 1988; Lyon et al., 1981; Meijers et al., 1988,1991; Minowa et al., 1988; Morabia et al., 1992; Une et al., 1995; Wu-Williams et al., 1993). However, lack of data on individual smoking behavior may have obscured results in some of these studies (Lyon et al., 1981; Meijers et al., 1988; Minowa et al., 1988). Importantly, a lower cancer potency of coal-mine dust versus coal particles of incomplete combustion (PIC) might be expected based on the greater concentrations of mutagenic compounds in the former (IARC, 1997).

Of three Northern Chinese residential fuel types, only "smoky" coal has been linked to increased lung cancer mortality; neither "smokeless" coal nor wood fuel were associated with any significant effect (Band et al., 1990; Chapman et al., 1988; de Koning and Smith, 1984; Mumford et al., 1987,1989,1990). Smoky coal is comparable to U.S. medium-volatile bituminous coal of low sulfur content, whereas smokeless coal is more similar to hard coal such as lignite or anthracite (Mumford et al., 1987,1989). Despite heavy soot residue left by smoky coal, its use in China may have persisted due to its ability to rapidly generate large amounts of heat, as measured in British thermal units (Btu). PIC from smoky or bituminous coal are associated with elevated lung cancer mortality in laboratory animals (Liang et al., 1988; Pott and Stöber, 1983). When burned, smoky coal emits higher levels of sub-micron organic PIC versus wood or smokeless coal, which are mutagenic in Ames Salmonella bioassays (Mumford et al., 1987,1990). Lung cancer has been induced in mice exposed to coal smoke and skin cancer development has occurred in mice treated topically with filtered organic coal extracts.(Mumford et al., 1990) Polycyclic aromatic hydrocarbon (PAH) components of PIC, such as benzo(a)pyrene, dibenzo $(a, l)$ pyrene, and 7,12-dimethylbenz(a)anthracene are effective experimental and 
suspected human carcinogens (Chuang et al., 1992; Cupitt et al., 1994; de Koning and Smith, 1984; Higginbotham et al., 1993; Mumford et al., 1989). Elevated PAH-DNA adducts and urinary PAH levels have been associated with residential smoky coal (He et al., 1991; Mumford et al., 1993,1995).

Cooking and heating fuels are among sources of residential air pollution. Until the 1950's, coal and wood were the predominant fuels burned in U.S. homes (USBC, 1953). Perhaps due to steady replacement by natural gas and electricity, few studies have examined the public health impact of coal and wood combustion in U.S. homes (Lambert, 1997; Samet et al., 1987,1988; USBC, 1953). Indoor wood smoke has been linked to several respiratory illnesses, while indoor coal smoke has been measured in U.S. homes but not studied in association with human health (Yocom et al., 1971; Cooper, 1980; de Koning and Smith, 1984; Dennis et al., 1996; Honicky et al., 1985; Liang et al., 1988; Marbury, 1991; Mumford et al., 1989; Robin et al., 1996; Tuthill, 1984).

This ecological analysis examined the relation of U.S. domestic bituminous coal consumption to age-specific lung cancer mortality (LCM) in U.S. white females dying during 1950-54, the great majority of whom never smoked (particularly those $\geq 60$ years old). A comparative analysis of these rates within different age ranges $(40+$ vs. $60+)$ provided a way to assess the potential confounding effect of inter-county differences in (rather low) smoking prevalence on any association observed between LCM and coal use, as explained below. Socio-demographic, climatic, and geophysical covariates were also examined. The present study is the first nationwide evaluation of a relationship between coal use and lung cancer in the U.S. 


\subsection{Materials and Methods}

County-level LCM data for the states AL and HI were unavailable, in the case of VA included unreliable mortality rates, and for the major retirement states $(\mathrm{CA}, \mathrm{AZ}$, and FL) corresponded to a relatively low percent $(<70 \%)$ of lifetime residence within 25 miles of that at the time of death compared to other states (Cohen, 1992b; Marsh et al., 1996). Therefore, a total of 2,821 counties were considered in this analysis, including those in $\mathrm{AK}, \mathrm{AZ}, \mathrm{CA}, \mathrm{FL}, \mathrm{HI}$ and VA (as in Section 2). Because socioeconomic status and other demographic covariates may influence indoor air pollution exposure (Lebowitz, 1983), adjustment was performed on several demographic factors for which U.S. county-level data could be obtained as classified below.

Lung Cancer Mortality Data. U.S. county-level mortality rates (deaths per person-

year) were obtained for lung cancer (bronchus, trachea, + lung; ICDA 162-163, $6^{\text {th }}$ Revision) during 1950-54 in white females by 5-year age intervals (Marsh et al., 1996). Due to the rarity of female lung cancer at that time, particularly in younger age groups, data on women under age 40 were excluded and age-specific data were combined into $10-$ year age intervals $(40-49,50-59,60-69,70-79,80+)$.

Analyses were carried out for all women (40+ years) and also for women aged $60+$. The latter restriction addressed potential (inter-county) confounding due to cigarette smoking insofar as smoking prevalence in 1950-54 among U.S. white females aged $60+$ vs. $40+$ was approximately $5 \%$ vs. approximately $11 \%$, respectively, and women aged $60+$ smoked fewer cigarettes and started smoking at a later age than women aged $40+$ (Garfinkel, 1981; Haenszel and Shimkin, 1956; Haenszel et al., 1956). Based on these historical smoking data, excess risk for elevated LCM in white women dying at age $40+$ 
(vs. 60+) in 1950-54 was estimated to be 0.74 (vs. 0.16) for women aged $40+$ (vs. 60+) compared to expected LCM risks for never-smoking women who died during this period. This estimated 4- to 5-fold difference in excess risk indicates that any ecological association observed between indoor BC use and female LCM due solely to inter-county confounding by smoking should be greatly reduced in analyses involving older women (aged 60+) compared to those involving all women considered (aged 40+).

Coal Data. The number and percent of homes using coal for (central + noncentral) heating in 1940 were obtained from U.S. census data (USBC, 1943). Because Mumford demonstrated that "smoky" or bituminous coal, and not anthracite or "smokeless" coal, is associated with increased female LCM, our study focused on domestic $\mathrm{BC}$ consumption per se within counties that used mainly coal for heating (Mumford et al., 1987,1989). County-level data for the year 1918 on domestic per capita net tons of $\mathrm{BC}$ consumption (fuel utilization in housing units/residences, apartment buildings, and small local businesses) were obtained from a detailed map published by the U.S. Fuel Administration (Lesher, 1919). Similarly detailed data could not be obtained for other years. Binned quartiles of 1918 BC consumption were used as an index of residential coal exposure to coal smoke in our analysis. The LCM data used were based on deaths among all residents of a county, but not all persons living in U.S. counties burned coal. We therefore focused specifically on counties in which a substantial fraction of homes burned coal as fuel by restricting the analysis to counties in which $\geq 75 \%$ of homes used coal for heating.

Females dying between 1950-54 reached ages 29-33 (the approximate midpoint of their lives) by 1918 , which is the year of the coal-use data considered in the present 
analysis. To examine the potential impact any changes in net tons $\mathrm{BC}$ consumed (NTBCP) per capita between 1918 and 1940, county-level consumption for nine U.S. regions in 1918 was compared to corresponding 1940 U.S. regional summary data on average tons of BC consumed per dwelling unit (TBCD) (Bituminous Coal Institute, 1948). To convert from TBCD to NTBCP, regional 1940 populations were divided by dwelling units per region in 1940, weighted by the fraction of $1940 / 1950$ regional populations, with removal of states not considered (as discussed). The 1918 NTBCP data were also weighted as a fraction of the 1950 population for direct comparison to 1940 TBCD. Regions were subsequently categorized into two groups based on whether $B C$ use in 1940 was < or was $\geq 1$ NTBCP; the two groups had a mean ( \pm 1 SDM) BC use level of 0.89 $( \pm 0.036)$ and $1.9( \pm 0.053) \mathrm{NTBCP}$, respectively. This BC-use category was used as an additional adjustment variable in our analysis, to examine the potential effect of different patterns of change in BC use subsequent to 1918, at least at a regional level.

Demographic Data. Census data on the following 1950 county-level sociodemographic variables were obtained: total population, population density, U.S. region (among nine regions considered), urban population, rural-farm population, educational level (total years), income (median family income), migration (number of persons living in different county or abroad in 1949 vs. 1950), females in the workforce (\%), and persons employed in agriculture (\%); income grouped as rich ( $\% \geq \$ 5,000$ income) vs. poor $(\%<$ $\$ 2,000$ income); and educational level dichotomized as uneducated ( $\%<$ grade 5$)$ vs. highly educated (\% $\geq$ high school) (USBC, 1953). These socio-demographic variables were evaluated as corresponding county quintile values, using 1950 county populations as weights. 
Geophysical and Nutrient Data. Respiratory exposure to radon is associated with increased lung cancer risk in animals and underground miners, and so was included as an adjustment variable (Bogen, 1997,1998; NRC, 1988). Clinical trials and prospective studies have indicated that dietary selenium intake may be protective against cancer development at specific sites, including the lung (Blot et al., 1993; van den Brandt et al., 1993). Additionally, climatic factors which might influence indoor coal smoke concentration were included for adjustment. Geophysical variates considered at the U.S. county-level were: annual average residential radon estimates; a 3-level index of dietary selenium exposure based on corresponding data on selenium content in local foliage; and five 1953-75 "typical" climatic measures, including daily hours of precipitation, January/July temperatures, wind speed, and heating infiltration degree days or "heating IDD" which correlates with energy use for home heating (Apte et al., 1997; Clark et al., 1991; Price et al., 1998). Residential radon estimates used for this purpose were derived from county-specific U.S. Environmental Protection Agency survey data, adjusted for additional geophysical and climatic factors using Monte Carlo and regression techniques (Price et al., 1998).

Statistical Analysis. Adjusted relative risk (RR) estimates and confidence intervals were calculated using maximum-likclihood estimation, and corresponding adjusted chisquare tests for trend were performed (Breslow and Day, 1987b). RR estimates were computed using a standardized slope, $\mathrm{B}_{\text {adj }}$ (in units of inverse per capita net tons of $\mathrm{BC}$ used), where $\mathrm{B}_{\text {adj }}=b_{\text {adj }} / a$, and where $b_{\text {adj }}$ (the adjusted LCM slope) and $a$ (the unadjusted LCM intercept) were estimated by standard methods (Fleiss, 1981). Standard deviation 
(SD) and coefficient of variation (CV) estimates for B were obtained assuming approximate lognormality of $b_{\text {adj }}$ and $a$.

Socio-demographic and geophysical variables were used for adjustment in combination with age separately for each age range (40+vs. $60+$ ), creating: 20 2-variate analyses (involving age with or without one other variable), and 190 3-variate analyses (involving age and two other variables) (Table 3). Fisher's chi-square test was used to determine the overall significance of $p$-values for adjusted trend obtained for each set of multiple tests conducted (Fisher, 1973). All statistical calculations were performed using Mathematica 3.0 software (Wolfram, 1996).

\subsection{Results}

Approximately $640(22.7 \%)$ of the 2,821 U.S. counties in 1940 were characterized by $75 \%$ or more homes heated by coal. Women aged $40+$ in "high coal-using" counties experienced an estimated 5,807 female LC deaths within 46,120,369 person-years (PY) of observation versus 4,059 LC deaths among 16,887,421 PY of observation for women aged $60+$. Across all counties for both age groups, a total of 14,296 LC deaths occurred in $113,999,028$ PY during the period of interest. Quartiles of BC consumption across high coal-using counties were $0.03,0.45,1.4$, and 2.4 net tons, from lowest to highest quartile, respectively.

Adjusted slope $\left(\mathrm{B}_{\mathrm{adj}}\right)$ and trend-test $\mathrm{p}$-values for the two-variate analyses (age and one other variate) are summarized in Table 2 for all women (aged 40+) and for older women (aged 60+). All adjustment combinations yielded significant statistics indicating a positive trend, and the estimated slopes for all women (aged 40+) were similarly distributed to those for older women (aged 60+). 
Table 3. Trend in Relative risk (RR) of 1950-54 female lung cancer mortality (LCM) among U.S. counties in which $\geq 75 \%$ of homes used coal for heating.*

\begin{tabular}{|c|c|c|c|c|c|c|}
\hline \multirow[b]{2}{*}{$\begin{array}{l}\text { Adjusted for } \\
\text { age and: }\end{array}$} & \multicolumn{3}{|c|}{ Age $\geq 40 y$} & \multicolumn{3}{|c|}{ Age $\geq 60 y$} \\
\hline & $\begin{array}{l}\text { Slope } \\
(\times 100)\end{array}$ & $\begin{array}{l}\mathrm{CV}^{* *} \\
( \pm \%)\end{array}$ & $\begin{array}{l}-\log _{10} p \\
\text { for } \chi^{2}\end{array}$ & $\begin{array}{l}\text { Slope** } \\
(\times 100)\end{array}$ & $\begin{array}{l}\mathrm{CV}^{* *} \\
( \pm \%)\end{array}$ & $\begin{array}{l}-\log _{10} P \\
\text { for } \chi^{2} \text { trend }\end{array}$ \\
\hline Age only & 9.8 & 38 & 7.2 & 9.2 & 27 & 4.2 \\
\hline Agriculture & 9.3 & 28 & 6.5 & 9.9 & 27 & 5.0 \\
\hline Density & 9.4 & 26 & 6.6 & 9.9 & 23 & 5.0 \\
\hline Female work & 7.9 & 31 & 4.6 & 9.2 & 27 & 4.2 \\
\hline Heating IDD & 11.0 & 30 & 8.5 & 11.0 & 31 & 6.0 \\
\hline High school & 11.0 & 30 & 6.3 & 10.0 & 31 & 4.2 \\
\hline Income & 7.6 & 32 & 4.2 & 8.1 & 30 & 3.3 \\
\hline Migration & 11.0 & 25 & 9.3 & 12.0 & 25 & 6.8 \\
\hline Poor & 8.3 & 28 & 5.0 & 8.9 & 27 & 4.0 \\
\hline PrecipHr & 9.3 & 33 & 6.2 & 10.0 & 32 & 5.1 \\
\hline Region & 17.0 & 20 & 12 & 16.0 & 22 & 7.7 \\
\hline Rich & 6.9 & 38 & 3.4 & 7.7 & 35 & 2.9 \\
\hline $\mathrm{Rn}$ & 7.2 & 35 & 3.6 & 7.7 & 34 & 2.8 \\
\hline Rural & 8.6 & 29 & 5.7 & 9.4 & 27 & 4.5 \\
\hline School & 8.4 & 40 & 4.9 & 9.4 & 38 & 4.1 \\
\hline SeBin & 10.0 & 31 & 7.7 & 11.0 & 32 & 5.6 \\
\hline TempJan & 11.0 & 27 & 8.7 & 11.0 & 26 & 6.4 \\
\hline TempJul & 9.3 & 31 & 6.3 & 10.0 & 30 & 5.0 \\
\hline Uneduc & 9.0 & 30 & 5.9 & 10.0 & 26 & 5.0 \\
\hline Urban & 7.8 & 32 & 4.5 & 8.7 & 30 & 3.8 \\
\hline Wind & 7.3 & 44 & 3.4 & 6.5 & 53 & 2.0 \\
\hline
\end{tabular}

${ }^{*}$ LCM was compared among 4 groups of counties classified by annual per capita BC use (net tons), after adjusting for the following factors (each classified into U.S.county quintiles unless specified otherwise): $\mathrm{AgWork}=\%$ employed in agriculture, Density $=$ persons $/ \mathrm{km}^{2}$, FemWork $=\%$ females in total labor force, Heating IDD = heating infiltration degree-days, High school $=\%$ completed high school or more, Income $=$ median family income, Migration $=\#$ persons who lived in different county or abroad in 1949 vs. 1950, Poor $=\%$ with income $<\$ 2000$, PrecipHr $=$ daily hours of precipitation, Region $=$ location within 9 U.S. divisions, Rich $=\%$ with income $>\$ 5000$, Rural $=$ rural farm population, School $=$ median school years completed, SeBin $=$ index $(0,1$, or 2$)$ of relative exposure to dietary selenium, TempJan $/$ TempJul $=$ daily mean temperature for indicated month, Uneducated $=\%$ who completed $<$ grade 5 , Urban $=$ urban population, Wind $=$ mean daily wind speed.

${ }^{*}$ Slope $=$ normalized RR slope $(B)=$ (factor-adjusted slope of LCM as a linear function of $\mathrm{BC}$, by person-year-weighted regression)/(unadjusted intercept of corresponding linear fit); $\mathrm{CV}=100 \% \times\left(\mathrm{SD}_{\text {slope }} /\right.$ Slope $)$; see Materials and Methods. 
Results of the three-variate analyses (age and two other variates) for all women (aged $40+$ ) and older women (aged 60+) are summarized in Figure 6 by corresponding cumulative distributions of $B_{\text {adi }}$, plotted together with corresponding lower and upper $( \pm 1$ $\mathrm{SD})$ bounds on $\mathrm{B}_{\mathrm{adj}}$ and (-log inverse) p-values for adjusted tests of trend. The $\mathrm{p}$-values distributions in Figure 6 indicate that significant trends were obtained for almost all three-variate adjustment combinations. Comparing highest vs. lowest $\mathrm{BC}$-use quartile among women aged $40+$, simultaneous adjustment for wind and region with age showed the most significant LCM/BC-use relationship for three-variate analyses, with $R_{\mathrm{adj}}=$ $1.68(1.28,2.21)$ and $\mathrm{p}<10^{-9}$ for adjusted trend while simultaneous adjustment for region and age from two-variate analyses resulted in the most significant LCM/BC-use association, with $\operatorname{RR}=1.54(1.25,1.9)$ and $p<10^{-13}$ for adjusted trend. Similar findings for women aged $60+$ were obtained for these variable combinations. The percent of $p$-values $\geq 0.05$ was $3 \%$ for women aged $40+$ and $6 \%$ for women aged $60+$, i.e. no greater than might be expected by chance. Fisher $\chi^{2}$ values for the overall significance of the sets of $190 \mathrm{p}$ values obtained for three-variate analyses involving $40+$ and $60+$ women were highly significant $\left(\chi^{2}=4490.5\right.$ and $\mathrm{p} \approx 0$ for $40+, \chi^{2}=3363.7$ and $\mathrm{p} \approx 0$ for $\left.60+\right)$.

Adjustment for BC use in 1918 vs. 1940 produced similarly significant results when two- and three-variate analyses were repeated.

\subsection{Discussion}

Overall, BC consumption in 1918 was shown to be significantly associated with female LCM in 1950-54 for counties of high coal use after statistical adjustment for numerous combinations of variates (Table 3, Figure 6). Importantly, this significant positive LCM-BC association was observed in two female age groups, $40+$ and $60+$, whose 

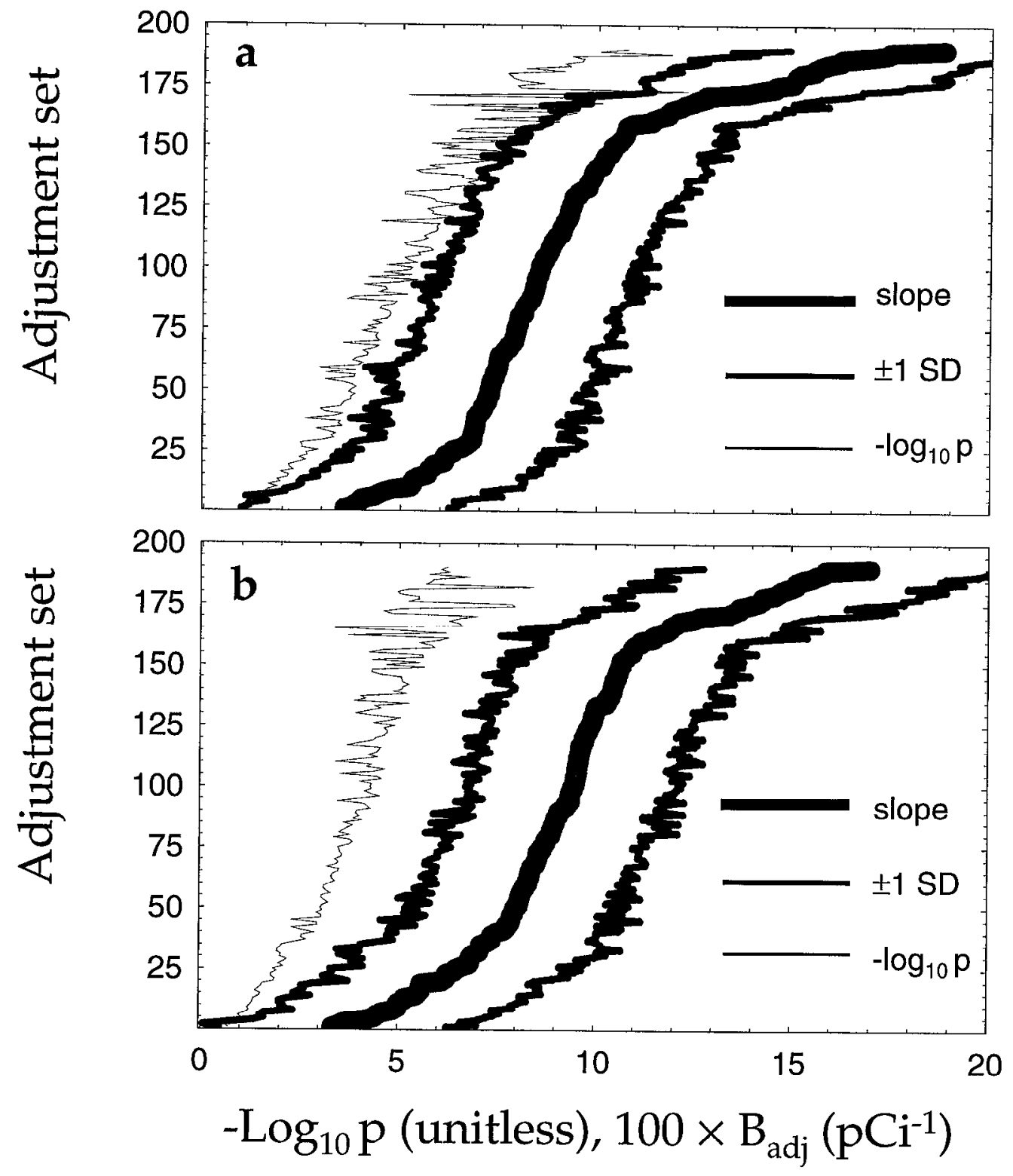

Figure 6. Adjusted relative-risk slopes and corresponding p-values for adjusted trend in 190 analyses adjusting for age and two additional variates, (among those listed in Table 3) are shown for U.S. females (a) 40+, and (b) 60+, years of age. Cumulative distributions of norm alized adjusted slope $\left(B_{\text {adj }}\right)$ are surrounded by correspon ding lower and upper ( $\pm 1 \mathrm{SD})$ bounds; corresponding $\mathrm{p}$-values plotted as $\left(-\log _{10} \mathrm{p}\right)^{-1}$ for adjusted tests of trend are overlaid. Slope values refer to relative risk of lung cancer mortality (LCM) based on comparisons of highest ( $>2.4$ net tons) vs. lowest ( $\leq 0.03$ net tons) county quartiles of bituminous coal use, with slope calculated as $\mathrm{B}_{\text {adj }}=b_{\text {adj }} / a$ where $b_{\text {adj }}=$ the adjusted LCM slope and $a=$ the unadjusted LCM intercept. 
1955 smoking prevalence (approximately 11\% and 5\%) differed markedly (Haenszel and Shimkin, 1956; Haenszel et al., 1956), which is consistent with the hypothesis that confounding by smoking is unlikely to explain the observed association.

Inherent limitations of the ecological study design (Greenland, 1992; Greenland and Morgenstern, 1989; Greenland and Robins, 1994; Piantadosi, 1994; Piantadosi et al., 1988) are countered by several unique features of the present study. The wide investigative scope achieved from evaluating 640 U.S. counties of high coal use was a major strength. Cigarette smoking, the most significant risk factor for lung cancer, was addressed by performing a restricted analysis with women aged 60+, who smoked roughly half as much as all women combined (40+). While intra-county associations between low-prevalence smoking and coal use cannot be ruled out as explaining the observed association between BC use and female LCM, the consistency of the observed effect among women aged $40+$ vs. $60+$ indicates that the BC-LCM association is not likely due to inter-county confounding by cigarette smoking.

Because of concern over the constancy of $\mathrm{BC}$ use during the lifetime of women dying in 1950-54, the LCM-BC relationship was compared regionally in 1940 vs. 1918. Similar findings after adjustment for regional BC use patterns of 1940 indicate that this relationship docs not appear to be attributable to changes in geographic patterns of BC use between 1918 and 1940.

Burning rate of fuel, type of stove, and coal rank have all been shown to impact the amount of indoor pollution generated (McCrillis and Burnet, 1990; Mumford et al., 1989; Mumford et al., 1987). While burning rate and stove-type data were not available, our focus on consumption of bituminous coal was intended to address this matter. 
Additionally, insofar as home ventilation is an important aspect of indoor air pollution, heating IDD was used to examine any potential effect of home energy use that would typically correlate with reduced home ventilation and greater indoor air pollutant concentration.

\section{Effect of Radon Exposure on Liver Foci in Japanese Medaka: An Experimental Test of CD2-Model Predictions}

\subsection{Background}

Experimental work conducted as part of this LDRD-sponsored project culminated a collaboration with Mark Okihiro, D.V.M., Ph.D., and Professor David Hinton at the University of California, Davis (U.C. Davis), School of Veterinary Medicine. These experimental work involved subchronic exposure of three groups of 148 Japanese medaka fish (rice-fish minnows) to different aqueous concentrations of radon gas. The purpose of the study was to examine effects of alpha exposure (arising from the decay of radon, which partitions into fish livers at a concentration proportional to that of radon in tank water) on the occurrence and growth of premalignant cells (namely, enzymatically altered proliferative "foci") in the livers of young fish exposed subchronically to different concentrations of radon gas. Specifically, the study was conducted to test the CD2-based hypothesis that alpha exposure should increase the frequency but retard the growth of liver foci. Fish liver foci were studied because: many fish can be exposed and studied economically, proliferative foci in liver (as opposed to most other tissues) can be identified and 
examined by staining techniques, the response of liver foci in Japanese medaka to chemical carcinogens has been studied for decades.

\subsection{Materials and Methods}

Three weeks after the medaka were hatched at U.C. Davis, the fish were all "initiated" to increase the naturally low, spontaneous occurrence of liver foci in these fish to larger, more easily detected frequencies. Initiation was done by exposing them for 1 hour to a 500-ppm concentration of the direct-acting mutagen and liver carcinogen, diethylnitrosamine (DEN). Four weeks later at LLNL, the fish were separated into three specially modified 80-liter fish tanks: a control tank, and two tanks with water containing elevated concentrations of radon gas, derived from a $10-\mathrm{mCi}$ radium source through which 100 to $500 \mathrm{~mL} / \mathrm{min}$ of dry air was directed. To maintain different radon concentrations in tank water, air containing a background level, a low, or a higher radon concentration was sparged continuously into the corresponding tank water throughout the exposure period. Dried room air was used to dilute radon-enriched air from the radium source. All tanks were located within a single hood, illuminated from above with three 30-inch VitaGlow ${ }^{\circledast}$ fluorescent lamps operated using a 12-h light/dark cycle.

Each tank was sealed on top using air-tight fittings, and kept filled with between 70 and 72 liters of purified, reconstituted water (Recon) optimized for medaka growth, which was maintained at $25 \pm 1{ }^{\circ} \mathrm{C}$ and $\mathrm{pH}=7.6$. Each tank included a thermostat, and one biofilter drawing air from the tank headspace; after the sixth week of exposure identical submerged power filters and sintered-glass bacterial 
matrices were added to each tank to enhance biofiltration efficiency. From 10 to $20 \%$ of the water from each tank was replaced with fresh Recon once per week. Sparge and biofilter air were circulated (with a combined flow rate of $\sim 70 \mathrm{~mL} / \mathrm{min}$ ) through each tank by an air-flow control unit adjacent to the hood containing the tanks; the unit also directed samples of sparge and biofilter air from each tank to two corresponding RD-200 monitors that measured corresponding radon+daughter activity in air sampled for $30 \mathrm{~min}$ from each source on a continually rotating basis. A tank-air outflow of $\sim 30 \mathrm{~mL} / \mathrm{min}$, equal to the sparge air inflow, was released from a small port on each tank into the hood. Tank water was sampled periodically by gas-tight syringe through a small port to monitor $\mathrm{pH}$ and radon, nitrite, nitrate, oxygen, and ammonia concentrations. Fish were manually fed pre-weighed amounts (totaling $\sim 5 \%$ of body weight per day) of fine-grade UCD-prepared medaka food, dispensed 2 to 4 times/day.

After 10 weeks of exposure, 40 fish were harvested from each tank, and all remaining fish were sacrificed 4 weeks later. After sacrifice, each fish was weighed and its liver was excised, fixed in formalin, and prepared for sectioning into slides for histological examination and quantitative morphometry of liver foci.

A separate experiment was conducted after the 14-week radon exposure to measure the equilibrium tissue:water partition coefficient for radon gas partitioned between tank water and soft (relatively rapidly perfused) medaka tissue. In this experiment, 111 fish were maintained for $48 \mathrm{~h}$ in a large nylon net within the sealed high-concentration tank containing an approximate mean radon concentration of $40,000 \mathrm{pCi} / \mathrm{L}$ over that period. Over a period of $\sim 1 \mathrm{~min}$, these netted fish were then 
removed from the tank, drained, blotted dry on tissue paper, rinsed in a 10-L bucket of Recon, and (still contained within a small portion of netting cut from the original netting) finally placed into a 4-L Nalgene jar pre-filled with $3.5 \mathrm{~L}$ of Recon. The jar was then sealed with a screw cap including fittings allowing $500 \mathrm{~mL} / \mathrm{min}$ of dry air to be bubbled into the bottom of the jar, with air collected at the top directed into one of the RD-200 counters mentioned above for a period of $1.5 \mathrm{~h}$, after which the fish were euthanized and weighed.

Counts from jar air measured over a 60 -min period were compared to counts measured in one subsequent and two previous control experiments, before and after each of which the 4-L jar was thoroughly rinsed with Recon and the air lines were purged until no counts above background were detected. The two previous control experiments involved measuring counts for $60 \mathrm{~min}$ after direct injection of $10 \mathrm{~mL}$ of water from the tank from which the 111 fish (weighing a total of $19.9 \mathrm{~g}$ ) were removed shortly thereafter. In the subsequent control experiment, the same small piece of netting used to place the 111 fish into the 4-L jar was placed back into the sealed tank from which the fish were taken, allowed to re-equilibrate with radon in tank water for $15 \mathrm{~min}$, and then placed into the pre-filled jar for measuring released radon as before. Counts measured from the jar containing fish plus netting, less those measured from the jar containing just the netting, were compared to those measured after injection of $10 \mathrm{~mL}$ of tank water to determine the amount of radon removed from the fish compared with that contained in tank water. 


\subsection{Results}

From the separate experiment conducted after the 14-week radon exposure, was determined that, at equilibrium, radon is about 1.5- to 3-fold more concentrated in rapidly perfused medaka tissue than in surrounding tank water. About $16 \%$ of all the fish exposed over 10 to 14 weeks died prior to sacrifice; mortalities occurred more often in the low-concentration tank, compared to the control and highconcentration tanks. The examination of fish livers is currently being completed at U.C. Davis.

\section{Conclusions}

In conclusion, modeling results from this LDRD study support the biological plausibility of the hypothesis that LCM is not increased by exposure to radon at residential levels. They are consistent with a mechanistically based U-shaped (or "hormesis") dose-response pattern for radon's effect on lung-cancer risk, but by no means prove that this pattern either is the case or is as large as suggested by the U.S. ecologic data considered. The U-shaped CD2 fit obtained as described in Section 2 differs sharply from linear-no-threshold models currently used to extrapolate lungcancer risks for low-level radon exposures. The analysis described in Section 3 supports the hypothesis that ecologic data meaningfully contributed to the CD2-fit to residential and occupational radon-vs.-LCM data described in Section 2, insofar as the same ecologic data reveal a significant positive association between lifetime 
bituminous (smoky) coal use and LCM in U.S. women during 1950-54, in agreement with both ecologic and case-control studies on LCM vs. coal use among women in China. The present study thus indicates that some consideration of fundamental model uncertainty ought to play a more important role in risk management for residential radon (Bogen and Layton, 1998). Furthermore, the results obtained pose testable mechanistic hypotheses concerning the effect of subchronic or chronic exposure to relatively cytotoxic genotoxins, such as alpha radiation, on growth kinetics of premalignant foci. One such test, described in Section 4 above, is being completed as part of this study.

Acknowledgment

Work performed under the auspices of the U.S. Department of Energy by Lawrence Livermore Nationa1 Laboratory under contract W-7405-ENG-48. 


\section{References}

Alavanja, M. C. R., Brownson, R. C., Lubin, J. H., Berger, E., Chang, J., and Boice Jr., J. D. (1994). Residential radon exposure and lung cancer among nonsmoking women. J. Natl. Cancer Inst. 86, 1829-1837.

Ames, R. G., Amandus, H., Attfield, M., Green, F. Y., and Vallyathan, V. (1983). Does Coal Mine Dust Present a Risk for Lung Cancer? A Case-Control Study of U.S. Coal Miners. Archives of Environmental Health 38, 331-333.

Apte, M. G., Nero, A. V., and Rezvan, K. L. (1997). Meteorological database for the United States. Indoor Air 8, 1-7.

Armitage, P., and Doll, R. (1957). A two-stage theory of carcinogenesis in relation to the age distribution of human cancer. Br. J. Cancer 11, 161-169.

Armstrong, B. K., McNulty, J. C., Levitt, L. J., Williams, K. A., and Hobbs, M. S. T. (1979). Mortality in Gold and Coal Miners in Western Australia with Special Reference to Lung Cancer. British Journal of Industrial Medicine 36, 199-205.

Band, P. R., Spinelli, J. J., Gallegher, R. P., Threlfall, W. J., Ng, V. T. Y., Moody, J., Raynor, D., Svirchev, L. N., Kan, D., and Wong, M. (1990). Identification of Occupational Cancer Risks Using a Population-Based Cancer Registry. Cancer Results in Cancer Research 120, 106-121.

Barrass, N. C., Price, R. J., Lake, B. G., and Orton, T. C. (1993). Comparison of the acute and chronic mitogenic effects of the peroxisome proliferators methylclofenapate and clofibric acid in rat liver. Carcinogenesis 14, 1451-1456.

Bertalanffy, F. D. (1968). Dynamics of cellular populations in the lung. In "The Lung." (A. A. Liebow, and D. E. Smith, Eds.), pp. 19-30. The Williams \& Wilkins Company, Baltimore.

Bertrand, J. P., Chau, N., Patris, A., Mur, J. M., Pham, Q. T., Moulin, J. J., Morviller, P., Auburtin, G., Figueredo, A., and Martin, J. (1987). Mortality Due to Respiratory Cancers in the Coke Oven Plants of the Lorraine Coalmining Industry (Houillères du Bassin de Lorraine). British Journal of Industrial Medicine 44, 559565.

Bituminous Coal Institute. (1948). "Bituminous Facts and Figures: Mining, Distribution, Consumption." Bituminous Coal Institute, Washington, DC.

Blot, W. J., Li, Y.-J., Taylor, P. R., Guo, W., Dawsey, S., and Wang, G.-Q. (1993). Intervention trials in Linxian, China: Supplementation with specific vitamin/mineral combinations, cancer incidence, and disease-specific mortality in the general population. J. Natl. Cancer Inst. 85, 1483-1492.

Bogen, K. T. (1997). Do U.S. county data disprove linear no-threshold predictions of lung cancer risk for residential radon? - A preliminary assessment of biological plausibility. Human Ecol. Risk Assess.

Bogen, K. T. (1998). Mechanistic model predicts a U-shaped relation of radon 
exposure to lung cancer risk reflected in combined occupational and U.S. residential data. Human Exper. Toxicol. 17, 691-696.

Bogen, K. T., and Layton, D. L. (1998). Risk management for plausibly hormetic environmental carcinogens: The case of radon. Human Exper. Toxicol. 17, 463467.

Boren, H. G., and Paradise, L. J. (1978). Cytokinetics of lung. In "Pathogenesis and therapy of lung cancer." (C. C. Harris, Ed.), pp. 369-419. Marcel Dekker, Inc., New York.

Breslow, N. E., and Day, N. E. (1987a). Statistical Methods in Cancer Research, Volume II--The Design and Analysis of Cohort Studies., pp. 106-118. International Agency for Cancer Research (IARC), Iyon.

Breslow, N. E., and Day, N. E. (1987b). "Statistical Methods in Cancer Research: The Design and Analysis of Cohort Studies." International Agency for Research on Cancer, Lyon.

Chapman, R. S., Mumford, J. L., Harris, D. B., He, X., Jiang, W., and Yang, R. (1988). The Epidemiology of Lung Cancer in Xuan Wei, China: Current Progress, Issues, and Research Strategies. Archives of Environmental Health 43, 180-185.

Chen, B. H., Hong, C. J., and He, X. Z. (1992). Indoor Air Pollution and its Health Effects in China - A Review. Environmental Technology 13, 301-312.

Chen, B. H., Hong, C. J., Pandey, M. R., and Smith, K. R. (1990). Indoor Air Pollution in Developing Countries. Rapp. trimest. statist. sanit. mond. 43, 127-138.

Chiang, C. L. (1984). The Life Table and its Applications, pp. 91-111. R.E. Krieger Publ. Co., Malabar, FL.

Chovil, A. C. (1979). Occupational Lung Cancer and Smoking: A Review in the Light of Current Theories of Carcinogenesis. CMA Journal 121, 548-555.

Chuang, J. C., Wise, S. A., Cao, S., and Mumford, J. L. (1992). Chemical Characterization of Mutagenic Fractions of Particles from Indoor Coal Combustion: A Study of Lung Cancer in Xuan Wei, China. Environ. Sci. Technol. 26, 999-1104.

Clark, L. C., Cantor, K. P., and Allaway, W. H. (1991). Selenium in forage crops and cancer mortality in U.S. counties. Arch. Environ. Health 46, 37-42.

Cockcroft, A., and Andersson, N. (1987). Radiological Irregular Opacities and Coalwork Exposure: A Case-referent Study. British Journal of Industrial Medicine 44, 484-487.

Cohen, B. L. (1992a). Compilation and integration of studies of radon levels in U.S. homes by states and counties. Crit. Rev. Environ. Control 22, 243-364.

Cohen, B. L. (1992b). Percentage of lifetime spent in area of residence at time of death. Environ. Res. 57, 208-211.

Cohen, B. L. (1995). Test of the linear-no threshold theory of radiation carcinogenesis 
for inhaled radon decay products. Health Phys. 68, 157-174.

Cohen, B. L. (1997). Lung cancer rate vs. mean radon level in U.S. counties of various characteristics. Health Phys. 72, 114-119.

Cooper, J. A. (1980). Environmental Impact of Residential Wood Combustion Emmissions and its Implications. Journal of the Air Pollution Control Association 30, 855-861.

Costello, J., Ortmeyer, C. E., and Morgan, W. K. C. (1974). Mortality From Lung Cancer in U.S. Coal Miners. AJPH 64, 222-224.

Cupitt, L. T., Glen, W. G., and Lewtas, J. (1994). Exposure and Risk from Ambient Particle-bound Pollution in an Airshed Dominated by Residential Wood Combustion and Mobile Sources. Environmental Health Perspectives 102, 75-84.

Dalal, N. S., Petersen, M., Green, F. H. Y., and Vallyathan, V. (1991). Presence of Stable Coal Radicals in Autopsied Coal Miners' Lungs and its Possible Correlation to Coal Workers' Pneumoconiosis. Archives of Environemtnal Health 46, 366-372.

Darby, S., Whitley, E., Silcocks, P., Thakrar, B., Green, M., Lomas, P., Miles, J., Reeves, G., Fearn, T., and Doll, R. (1998). Case-control study of lung cancer and residential radon exposure in Southwest England [Abstract]. Epidemiology $\mathbf{9 ( 4}$ Supp1.), S108 (343 S).

Darby, S. C., Whitley, E., Howe, G. R., Hutchings, S. J., Kusiak, R. A., Lubin, J. H., Morrison, H. I., Tirmarche, M., Tomásek, L., Radford, E. P., Roscoe, R. J., Samet, J. M., and Yao, S. X. (1995). Radon and cancers other than lung cancer in underground miners: A collaborative analysis of 11 studies. J. Natl. Cancer Inst. 87, 378-384.

de Koning, H. W., and Smith, K. R. (1984). Biomass Fuel Combustion and Health. World Health Organization.

Dennis, R. J., Maldonado, D., Norman, S., Baena, E., Castano, H., Martinez, G., and Velez, J. R. (1996). Wood Smoke Exposure and Risk for Obstructive Airways Disease Among Women. Chest 109, 55S-56S.

Doll, R., and Peto, R. (1981). The causes of cancer: Quantitative estimates of avoidable risks of cancer in the United States. Journal of the National Cancer Institute 66, 1191-1308.

Dragan, Y. P., Hully, J., Crow, R., Mass, M., and Pitot, H. C. (1994). Incorporation of bromodeoxyuridine in glutathione S-transferase-positive hepatocytes during rat multistage hepatocarcinogenesis. Carcinogenesis 15, 1939-1947.

Emmelot, P., and Scherer, E. (1980). The first relevant stage in rat liver carcinogenesis: A quantitative approach. Biochim. Biophys. Acta 605, 247-304.

Fisher, D. R., Hui, T. E., and James, A. C. (1991). Model for assessing radiation dose to epithelial cells of the human respiratory tract from radon progeny. Radiat. Protect. Dosim. 38, 73-80. 
Fisher, R. A. (1973). Statistical Methods for Research Workers, pp. 99-101. Hafner, New York.

Fleiss, J. L. (1981). Statistical Methods for Rates and Proportions, pp. 143-146. John Wiley \& Sons, New York, NY.

Gao, Y.-T., Blot, W. J., Zheng, W., Ershow, A. G., Hsu, W. C., Levin, L. I., Zhang, R., and Fraumeni, J. F. J. (1987). Lung Cancer Among Chinese Women. International Journal of Cancer 40, 604-609.

Garfinkel, L. (1981). Time trends in lung cancer mortality among nonsmokers and a note on passive smoking. J. Natl. Cancer Inst. 66, 1061-1066.

Greenland, S. (1992). Divergent biases in ecologic and individual-level studies. Stat. Med. 11, 1209-1234.

Greenland, S., and Morgenstern, H. (1989). Ecological bias, confounding, and effect modification. Int. J. Epidemiol. 18, 269-274.

Greenland, S., and Robins, J. (1994). Invited Commentary: Ecologic studies-biases, misconceptions, and conterexamples. Am. J. Epidemiol. 139, 747-760.

Gustavsson, P., Gustavsson, A., and Hogstedt, C. (1988). Excess of Cancer in Swedish Chimney Sweeps. British Journal of Industrial Medicine 45, 777-781.

Haenszel, W., and Shimkin, M. B. (1956). Smoking patterns and epidemiology of lung cancer in the United States: Are they compatible? J. Natl. Cancer Inst. 16, $1417-1441$.

Haenszel, W., Shimkin, M. B., Miller, H. P., Milmore, B. K., and Conover, A. G. (1956). Tobacco Smoking Patterns in the United States; Addendum: Tobacco Consumption in the U.S., 1880-1955. U.S. Publc Health Service, Washington, D.C.

Harley, M. H. (1988). Interaction of $\alpha$ particles with bronchial cells. Health Phys. 55, 665-669.

He, X., Chen, W., Liu, Z., and Chapman, R. S. (1991). An Epidemiological Study of Lung Cancer in Xuan Wei County, China: Current Progress. Case-Control Study on Lung Cancer and Cooking Fuel. Environmental Health Perspectives 94, 9-13.

Heidenreich, W. F., Luebeck, E. G., and Moolgavkar, S. H. (1997). Some properties of the hazard function of the two-mutation clonal expansion model. Risk Anal. 17, 391-399.

Higginbotham, S., RamaKrishna, N. V. S., Johansson, S. L., Rogan, E. G., and Cavalieri, E. L. (1993). Tumor-initiating Activity and Carcinogenicity of Dibenzo[a,l]pyrene Versus 7,12-dimethylbenz[a]anthracene and Benzo[a]pyrene at Low Doses in Mouse Skin. Carcinogenesis 14, 875-878.

Hofmann, W., Crawford-Brown, D. J., Ménache, M. G., and Martonen, T. B. (1991). Carcinogenic risk of non-uniform alpha particle irradiation in the lungs: Radon progeny effects at bronchial bifurcations. Radiat. Protect. Dosim. 38, 91-97.

Honicky, R. E., Osborne III, J. S., and Akpom, C. A. (1985). Symptoms of Respiratory 
Illness in Young Children and the Use of Wood-Burning Stoves for Indoor Heating. Pediatrics 75, 587-593.

Hornung, R. W., and Meinhardt, T. J. (1987). Quantitative risk assessment of lung cancer in U.S. uranium miners. Health Phys. 52, 417-430.

International Agency for Cancer Research (IARC). (1997). "Monographs on the Evaluation of Carcinogenic Risks to Humans: Silica, Some Silicates., Coal Dust, and Para-Aramid Fibrils." IARC Press, Lyon.

Kauffman, S. L. (1980). Cell proliferation in the mammalian lung. Int. Rev. Exp. Pathol. 22, 131-191.

King, C. M., Gillespie, E. S., McKenna, P. G., and Barnett, Y. A. (1994). An investigation of mutation as a function of age in humans. Mutat. Res. 316, 79-90.

Kociba, R. J. (1978). Results of a two-year chronic toxicity and oncogenicity study of 2,3,7,8-tetrachlorodibenzo-p-dioxin in rats. Toxicol. Appl. Pharmacol. 46, 279-303.

Lambert, W. E. (1997). Combustion Pollution in Indoor Environments. In "Indoor Air Pollution and Health." (E. J. J. Bardana, and A. Montanaro, Eds.), pp. 83-103. Marcel Dekker, Inc., Portland.

Last, J. A., Warren, D. L., Pecquet-Goad, E., and Witschi, H. (1987). Modification by ozone of lung tumor development in mice. J. Natl. Cancer Inst. 78, 149-154.

Lebowitz, M. D. (1983). Health Effects of Indoor Pollutants. Annual Review of Public Health 4, 203-221.

Lesher, C. E. (1919). “The Report of the Distribution Division: 1918-1919, Part 1: The Distribution of Coal and Coke." U.S. Fuel Administration, Distribution Division, Washington, DC.

Létourneau, E. G., Krewski, D., Choi, N. W., Goddard, M. J., McGregor, R. G., Zielinski, J. M., and Du, J. (1994). Case-control study of residential radon and lung cancer in Winnipeg, Manitoba, Canada. Am. J. Epidemiol. 140, 310-322.

Levin, L. I., Zheng, W., Blot, W. J., Gao, Y.-T., and Fraumeni Jr., J. F. (1988). Occupation and Lung Cancer in Shanghai: A Case-control Study. British Journal of Industrial Medicine 45, 450-458.

Liang, C. K., Quan, N. Y., Cao, S. R., He, X. Z., and Ma, F. (1988). Natural Inhalation Exposure to Coal Smoke and Wood Smoke Induces Lung Cancer in Mice and Rats. Biomedical and Environmental Sciences 1, 42-50.

Liu, Q., Sasco, A. J., Riboli, E., and Hu, M. X. (1993). Indoor Air Pollution and Lung Cancer in Guangzhou, People's Republic of China. American Journal of Epidemiology 137, 145-154.

Liu, Z., He, X., and Chapman, R. S. (1991). Smoking and Other Risk Factors for Lung Cancer in Xuanwei, China. International Journal of Epidemiology 20, 26-31.

Lubin, J. H. (1998). On the discrepancy between epidemiologic studies in individuals of lung cancer and residential radon and Cohen's ecologic regression. Health 
Physics 75, 4-10.

Lubin, J. H., Boice, J. D., Edling, C., Hornung, R. W., Howe, G., Kunz, E., Kusiak, R. A., Morrison, H. I., Radford, E. P., Samet, J. M., Tirmarche, M., Woodward, A., and Yao, S. X. (1995a). Radon-exposed underground miners and inverse dose-rate (protraction enhancement) effects. Health Phys. 69, 494-500.

Lubin, J. H., Boice, J. D. J., and Samet, J. M. (1995b). Errors in exposure assessment, statistical power and the interpretation of residential radon studies. Radiat. Res. 144, 329-41.

Lubin, J. H., Boice Jr., J. D., Edling, C., Hornung, R. W., Howe, G., Kunz, E., Kusiak, R. A., Morrison, H. I., Radford, E. P., Samet, J. M., Tirmarche, M., Woodward, A., Yao, S. X., and Pierce, D. A. (1994). Lung cancer and radon: A joint analysis of 11 underground miners studies. NIH Publication No. 94-3644. U.S. National Institutes of Health, Bethesda, MD.

Luebeck, E. G., Cutis, S. B., Cross, F. T., and Moolgavkar, S. H. (1996). Two-stage model of radon-induced malignant lung tumors in rats: Effects of cell killing. Radiat. Res. 145, 163-173.

Lyon, J. L., Klauber, M. R., Graff, W., and Chiu, G. (1981). Cancer Clustering Around Point Sources of Pollution: Assessment by a Case-Control Methodology. Environmental Research 25, 29-34.

Marbury, M. C. (1991). Wood Smoke. In "Indoor Air Pollution: A Health Perspective." (J. M. Samet, and J. D. Spengler, Eds.), pp. 209-222. The Johns Hopkins University Press, Baltimore.

Marsh, G., Ehland, J., Sefcik, S., and Alcorn, C. (1996). Mortality and Population Data System (MPDS). University of Pittsburgh (Department of Biostatistics Technical Report), Pittsburgh, PA.

McCrillis, R. C., and Burnet, P. G. (1990). Effects of Burnrate, Wood Species, Altitude, and Stove Type on Woodstove Emissions. Toxicology and Industrial Health 5, 95-102.

Meijers, J. M. M., Swaen, G. M. H., Slangen, J. J. M., and vanVliet, C. (1988). Lung Cancer Among Dutch Coal Miners: A Case-Control Study. American Journal of Industrial Medicine 14, 597-604.

Meijers, J. M. M., Swaen, G. M. H., Slangen, J. J. M., vanVliet, K., and Sturmans, F. (1991). Long-Term Mortality in Miners with Coal Workers' Pneumoconiosis in the Netherlands: A Pilot Study. American Journal of Industrial Medicine 19, 4350.

Mendelsohn, M. L. (1990). The somatic mutational component of human carcinogenesis. In "Scientific Issues in Quantitative Cancer Risk Assessment." (S. H. Moolgavkar, Ed.). Kirkhäuser, Boston.

Mercer, R. R., Russell, M. L., and Crapo, J. D. (1991). Radon dosimetry based on the depth distribution of nuclei in human and rat lungs. Health Phys. 61, 117-130. 
Mills, C. A., and Porter, M. M. (1953). Tobacco-smoking habits in an American city. J. Natl. Cancer Inst. 13, 1283-1297.

Minowa, M., Stone, B. J., and Blot, W. J. (1988). Geographic Pattern of Lung Cancer in Japan and Its Environmental Correlations. Jpn. J. Cancer Res. 79, 1017-1023.

Moolgavkar, S. H. (1983). Model for human carcinogenesis: Action of environmental agents. Environ. Health Perspect. 50, 285-291.

Moolgavkar, S. H., Luebeck, E. G., Krewski, D., and Zielinski, J. M. (1993). Radon, cigarette smoke, and lung cancer: A re-analysis of the Colorado Plateau uranium miners' data. Epidemiol. 4, 204-217.

Morabia, A., Markowitz, S., Garibaldi, K., and Wynder, E. L. (1992). Lung Cancer and Occupation: Results of a Multicentre Case-Control Study. British Journal of Industrial Medicine 49, 721-727.

Morgenstern, H. (1982). Uses of ecologic analysis in epidemiologic research. Am. J. Publ. Health 72, 1336-1344.

Mumford, J. L., Chapman, R. S., Harris, D. B., He, X. Z., Cao, S. R., Xian, Y. L., and Li, X. M. (1989). Indoor Air Exposure to Coal and Wood Combustion Emissions Associated with a High Lung Cancer Rate in Xuan Wei, China. Environment International 15, 315-320.

Mumford, J. L., He, X. Z., Chapman, R. S., Cao, S. R., Harris, D. B., Li, X. M., Xian, Y. L., Jiang, W. Z., Xu, C. W., Chuang, J. C., Wilson, W. E., and Cooke, M. (1987). Lung Cancer and Indoor Air Pollution in Xuan Wei, China. Science 235, 217-220.

Mumford, J. L., Helmes, C. T., Lee, X., Seidenberg, J., and Nesnow, S. (1990). Mouse Skin Tumorigenicity Studies of Indoor Coal and Wood Combustion Emissions From Homes of Residents in Xuan Wei, China with High Lung Cancer Mortality. Carcinogenesis 11, 397-403.

Mumford, J. L., Lee, X., Lewtas, J., Young, T. L., and Santella, R. M. (1993). DNA Adducts as Biomarkers for Assessing Exposure to Polycyclic Aromatic Hydrocarbons in Tissues from Xuan Wei Women with High Exposure to Coal Combustion Emissions and High Lung Cancer Mortality. Environmental Health Perspectives 99, 83-87.

Mumford, J. L., Li, X., Hu, F., Lu, X. B., and Chuang, J. C. (1995). Human Exposure and Dosimetry of Polycyclic Aromatic Hydrocarbons in Urine from Xuan Wei, China with High Lung Cancer Mortality Associated with Exposure to Unvented Coal Smoke. Carcinogenesis 16, 3031-3036.

National Research Council (NRC). (1988). "Health Risks of Radon and Other Internally Deposited Alpha-Emitters - BEIR IV." NRC Committee on the Biological Effects of Ionizing Radiations (BEIR), National Academy Press, Washington, DC.

National Research Council (NRC). (1991). "Comparative Dosimetry of Radon in Mines and Homes." National Academy Press, Washington, DC. 
National Research Council (NRC). (1998). "Health Risks of Exposure to Radon, BEIR VI (prepublication copy)." NRC Committee on the Biological Effects of Ionizing Radiations (BEIR), National Academy Press, Washington, DC.

Pershagen, G. (1998). Residential radon and lung cancer-New aspects in risk assessment [Abstract]. Epidemiology 9(4 Supp1.), S108 (342 S).

Piantadosi, S. (1994). Invited commentary: Ecologic biases. Am. J. Epidemiol. 139, 761-764.

Piantadosi, S., Byar, D. P., and Green, S. B. (1988). The ecological fallacy. Am. J. Epidemiol. 127, 893-904.

Pott, F., and Stöber, W. (1983). Carcinogenicity of Airborne Combusion Products Observed in Subcutaneous Tissue and Lungs of Laboratory Rodents. Environmental Health Perspectives 47, 293-303.

Press, W. H., Teukolsky, S. A., Vetterling, W. T., and Flannery, B. P. (1992). "Numerical Recipes in FORTRAN - The Art of Scientific Computing." Cambridge University Press, New York, pp. 650-700.

Price, P. (1999). Estimated Distribution of County GSDs of Indoor Radon Concentrations. LBNL-42820. Lawrence Berkeley National Laboratory, Berkeley, CA.

Price, P. N. (1997). Predictions and maps of county mean indoor radon concentrations in the mid-Atlantic states. Health Phys. 72, 893-906.

Price, P. N., Revzan, K., and Nero, A. V. (1998). Estimated County Mean Radon Concentrations in the United States. Lawrence Berkeley National Laboratory, Berkeley, CA.

Puskin, J. S. (1992). An analysis of the uncertainties in estimates of radon-induced lung cancer. Risk Anal. 12, 277-285.

Qing, L., Wei, C., Hong, C., and Xing-Zhou, H. (1993). Risk Factors for Lung Cancer in Non-Smokers in Xuanwei County of China. Biomedical and Environmental Sciences 5, 112-118.

Raju, M. R., Eisen, Y., Carpenter, S., Jarrett, K., and Harvey, W. F. (1993). Radiobiology of $\alpha$ particles. IV. Cell inactivation by $\alpha$ particles of energies $0.4-3.5$ MeV. Radiat. Res. 133, 289-296.

Reid, L., and Jones, R. (1983). Experimental chronic bronchitis. Int. Rev. Exp. Pathol. 24, 335-382.

Robin, L. F., Lees, P. S. J., Winget, M., Steinhoff, M., Moulton, L. H., and Santosham, M. (1996). Wood-burning stoves and lower respiratory illnesses in Navojo children. Ped. Infect. Dis. J. 15, 859-865.

Robinson, D. R., Goodall, K., Albertini, R. J., O'Neill, J. P., Finette, B., Sala-Trepat, M., Moustacchi, E., Tates, A. D., Beare, D. M., Green, M. H. L., and Cole, J. (1994). An analysis of in vivo hprt mutant frequency in circulating T-lymphocytes in the normal human population: A comparison of four datasets. Mutat. Res. 313, 
227-247.

Rotstein, J., Sarma, D. S. R., and Farber, E. (1986). Sequential alterations in growth control and cell dynamics of rat hepatocytes in early precancerous steps in hepatocarcinogenesis. Cancer Research 46, 2377-2385.

Samet, J. M. (1989). Radon and lung cancer. J. Natl. Cancer Inst. 81, 745-757.

Samet, J. M., Marbury, M. C., and Spengler, J. D. (1987). Respiratory Effects of Indoor Air Pollution. Journal of Allergy and Clinical Immunology 79, 685-700.

Samet, J. M., Marbury, M. C., and Spengler, J. D. (1988). Health Effects and Sources of Indoor Air Pollution - Part II. Am Rev Respir Dis 137, 221-242.

Simmons, J. A., Cohn, P., and Min, T. (1996). Survival and yields of chromosome aberrations in hamster and human lung cells irradiated by alpha particles. Radiat. Res. 145, 174-180.

Smith, B. J., Field, R. W., and Lynch, C. F. (1998). Residential 222Rn exposure and lung cancer: Testing the linear no-threshold theory with ecologic data. Health Phys. 75, 11-17.

Stidley, C. A., and Samet, J. M. (1993). A review of ecologic studies of lung cancer and indoor radon. Health Phys. 65, 234-251.

Trainor, K. J., Wigmore, D. J., Chrysostomou, A., Dempsey, J. L., Seshadri, R., and Morley, A. A. (1984). Mutation frequency in human lymphocytes increases with age. Mech. Ageing Devel. 27, 83-86.

Tuthill, R. W. (1984). Woodstoves, Formaldehyde, and Respiratory Disease. American Journal of Epidemiology 120, 952-955.

U.S. Bureau of the Census (USBC). (1943). Sixteenth Census of the United States, 1940: Housing Volume 2, General Charactersitics, Parts 1-5. U.S. Department of Commerce. U.S. Government Printing Office, Washington, D.C.

U.S. Bureau of the Census (USBC). (1953). County and City Data Book 1952. U.S. Department of Commerce. U.S. Government Printing Office, Washington, D.C.

Une, H., Esaki, H., Osajima, K., Ikui, H., Kodama, K., and Hatada, K. (1995). A Prospective Study on Mortality Among Japanese Coal Miners. Industrial Health 33, 67-76.

van den Brandt, P. A., Goldbohm, R. A., van't Veer, P., Bode, P., Dorant, E., Hermus, R. J., and Sturmans, F. (1993). A prospective cohort study on selenium status and the risk of lung cancer. Cancer Research 53, 4860-5.

Whittemore, A. S., and McMillan, A. (1983). Lung cancer mortality among U.S. uranium miners: A reappraisal. J. Natl. Cancer Inst. 71, 489-499.

Wichmann, H. E., Kreuzer, M., Gerken, M., Dingerus, G., Wellmann, J., Keller, G., and Kreienbrock, L. (1998). Lung cancer risk due to radon in dwellings in Western Germany [Abstract]. Epidemiology 9(4 Suppl.), S45 (91-O).

Witschi, H., Espiritu, I., Peake, J. L., Wu, K., Maronpot, R., and Pinkerton, K. E. 
(1997). The carcinogenicity of environmental tobacco smoke. Carcinogenesis 18, 575-586.

Wolfram, S. (1996). "The Mathematica Book." Cambridge University Press, Cambridge, UK.

Wu-Williams, A. H., Xu, Z. Y., Blot, W. J., Dai, X. D., Louie, R., Xiao, H. P., Stone, B. J., Sun, X. W., Yu, S. F., Feng, Y. P., Fraumeni Jr., J. F., and Henderson, B. E. (1993). Occupation and Lung Cancer Risk Among Women in Northern China. American Journal of Industrial Medicine 24, 67-79.

Xu, Z.-Y., Blot, W. J., and Fraumeni Jr, J. F. (1986). Geographic variation of female lung cancer in China. Am. J. Public Health 76, 1249-1250.

Xu, Z.-Y., Blot, W. J., Xiao, H.-P., Wu, A., Geng, Y.-P., Stone, B. J., Sun, J., Ershow, A. B., Henderson, B. E., and Fraumeni Jr, J. F. (1989). Smoking, Air Pollution, and the High Rates of Lung Cancer in Shenyang, China. Journal of the Naitonal Cancer Institute $\mathbf{8 1 .}$

Yocom, J. E., Clink, W. L., and Cote, W. A. (1971). Indoor/Outdoor Air Quality Relationships. Journal of the Air Pollution Control Association 21, 251-259.

Zerban, H., Radig, S., Kopp-Schneider, A., and Bannasch, P. (1994). Cell proliferation and cell death (apoptosis) in hepatic preneoplasia and neoplasia are closely related to phenotypic cellular diversity and instability. Carcinogenesis 15,2467 2473.

Zheng, Q. (1995). On the MVK stochastic carcinogenesis model with erlang distributed cell life lengths. Risk Anal. 15, 495-502. 


\section{Appendix 1 \\ Mathematical Details of the CD2 Model}

Mathematical details of the CD2 model applied to radon are presented below, proceding from the summary description and notation in Figure 1 and Methods. (Note: dependence of variables on time $t$ is occasionally suppressed for convenience.) Rates $b_{T}$ and $d_{T}\left(\mathrm{y}^{-1}\right)$ denote mean birth and death/differentiation rates, respectively, for cell type $T=S, D, P, R$, or $Q$. It was assumed that $\left(b_{P} / b_{S}\right)=$ $\left(b_{Q} / b_{R}\right)=n=10$, based on values of $\sim 5$ to 20 reported in studies comparing growth kinetics in proliferative foci and surrounding normal tissues (Barrass et al., 1993; Dragan et al., 1994; Rotstein et al., 1986; Zerban et al., 1994). For non-cytotoxic conditions, it was assumed that: the rate $g\left(\mathrm{y}^{-1}\right)$ governs net growth of $P$ - and $Q$-cell foci (i.e., $\left.b_{P}-d_{P}=b_{Q}-d_{Q}=g\right), b_{S}=b\left(1-f_{R}\right), b_{R}=d_{S}=b$, and $d_{R}<<b$ (i.e., $d_{R} \approx 0$ ), where $b^{-}$ ${ }^{1}(\mathrm{y})$ is the mean $R$-cell turnover time. The rate $b=4 \mathrm{y}^{-1}$ was assumed for normal human segmental bronchial epithelium, consistent with the range of values measured in normal tracheobronchial epithelial cells of rats and hamsters (Bertalanffy, 1968; Boren and Paradise, 1978; Kauffman, 1980; Reid and Jones, 1983) and values used for purposes of human radon dosimetry (Fisher et al., 1991; Hofmann et al., 1991).

The rate $k_{\mathrm{r}}\left(\mathrm{y}^{-1}\right)$ of induced reproductive death was modeled as $E / \mathrm{D}_{0}$, with $\mathrm{D}_{0}$ taken to be the inverse-variance-weighted mean ( $35 \mathrm{cGy}$ ) of published $\mathrm{D}_{0}$ values for alpha-induced killing of human lung cells in vitro (Raju et al., 1993; Simmons et al., 1996). Mutation rates $m_{T}\left(\mathrm{y}^{-1}\right)$ were modeled as $b_{T} m_{i}(1+s E)$ or $b_{T} m_{i}{ }^{\prime}(1+s E)$, where the corresponding mean background mutation rates per cell division, $m_{i}$ and $m_{i}^{\prime}$ ( $i=1$ for $T=S$ or $R, i=2$ for $T=P$ or $Q$, prime only for $T=R$ or $Q$ ), were estimated in terms of (unitless) parameters $m$ and $w$ under assumptions that $m_{1}=m_{2}=m$ and $m_{1}^{\prime}=$ $m_{2}^{\prime}=w m$. Alpha-induced interphase (as opposed to reproductive) cell death was not modeled explicitly. Tumors were assumed to be lethal at time $t+\tau$ conditional 
on $M(t) \geq 1$, where tumor latency $\tau$ was assumed to be $5 \mathrm{y}$, consistent with the range of values used in previous radon-related studies (Darby et al., 1995; Hornung and Meinhardt, 1987; Moolgavkar et al., 1993; NRC, 1988,1998; Whittemore and McMillan, 1983). Cytodynamic relations among $S, D$, and $R$ cells were assumed to be governed by a deterministic, Verhulst feedback-inhibition submodel that specifies how $b_{R}$ increases to ensure that $S(t)+D(t)$ tends toward $S(0)=S_{0}$, under the assumptions that $D$ cells are "recognized" by $R$ cells as normal $S$ cells, and that $R(t)=$ $R(0)=R_{0}=f_{R} S_{0}$ for all $t$ (i.e., that the increases in $b_{R}$ to offset $R$-cell losses are virtually "instantaneous" on the time scale considered). It was assumed that $S_{0}=$ $10^{8}$ cells, based on estimates of basal vs. secretory cell populations in human lung (Harley, 1988; Mercer et al., 1991);

Equations (1)-(14) below give the corresponding birth and death rates specifying the $\mathrm{CD} 2$ model applied to radon in this study:

$$
\begin{aligned}
& b_{S}=b\left(1-f_{R}\right) \\
& d_{S}=b+k_{\mathrm{r}} \\
& b_{D}=0 \text { (by definition) } \\
& d_{D}=b\left(2-f_{R}\right) \\
& b_{R}=b+G(t) \\
& b_{P}=n b_{S} \\
& d_{P}=b_{P}-\left(g+k_{\mathrm{r}}\right) \\
& b_{Q}=n b \\
& d_{Q}=b_{Q}-g\left[1+c\left(b_{R} b^{-1}-1\right)\right],
\end{aligned}
$$

where $G(l)$ is defined by the Verhulst relations:

$$
\begin{aligned}
G(t) & =G(\infty)+a\left\{1-\left([S(t)+D(t)] / S_{0}\right)\right\} \\
\mathrm{d} S(t) / \mathrm{d} t & =(b+G(t)) f_{R} S_{0}+\left(b_{S}-d_{S}\right) S(t) \\
\mathrm{d} D(t) / \mathrm{d} t & =k_{\mathrm{r}} S(t)+\left(b_{D}-d_{D}\right) D(t)
\end{aligned}
$$

The constant $c$ (unitless) in Eq. (9) reflects an assumption that (unexposed basal) premalignant stem $(Q)$ cells respond to regenerative mitogenic signals via a death- 
rate decrease proportional to the increase in $R$-cell birth rate over its normal value, b. The parameter $a\left(\mathrm{y}^{-1}\right)$ in Eq. (10) governs the speed of $S$-cell replacement, and was assumed to be sufficiently large to justify the assumption used that $S(t) \mid E \approx S(\infty)$, where for sequential exposures $E_{i}$ during time intervals $\left\{t_{i-1}, t_{i}\right\}, S(t)$ is interpreted as $S_{i}\left(t-t_{i-1}\right)$ such that $S_{i}(0)=S_{i-1}(\infty)$ and $S_{0}(\infty)=S_{0}$, and where analogous relations were presumed for D. Consequently, after substituting Eqs. (1-4) into Eqs. (10-12) and some algebra, it follows that

$$
G(\infty)=\left[\frac{S(\infty)}{S_{0}}\left(b-\frac{k_{\mathrm{r}}}{f_{R}}\right)\right]-b=\left[\frac{1}{1+k_{r}\left[b\left(2-f_{R}\right)\right]^{-1}}\left(b-\frac{k_{\mathrm{r}}}{f_{R}}\right)\right]-b
$$

The CD2 model described was evaluated using the analytic solution to the 2stage stochastic (MVK) model with piecewise-constant parameters, which during each $i$ th interval (using his notation) involves corresponding rates of mean occurrence $\left(v_{i}\right)$, birth $\left(\beta_{i}\right)$, death $\left(\delta_{i}\right)$, and mutation $\left(\mu_{i}\right)$ of premalignant cells (Zheng, 1995). Dropping the $i$-subscript, the latter three rates correspond directly to the rates $b_{P}, d_{P}$, and $m_{P}$, or to the rates $b_{Q}, d_{Q}$, and $m_{Q}$, as defined above. The expressions used for $v$ in the $S \rightarrow P \rightarrow M$ and $R \rightarrow Q \rightarrow M$ processes were $f S_{0} m_{P}$ and $f_{R} S_{0} m_{Q}$, respectively. The corresponding process-specific hazard functions, $H_{S}(t)$ and $H_{R}(t)$, were presumed independent and cach calculated as described by Zheng (1995). The latter independence implies that the age-specific hazard function for the 6-parameter CD2 model described is simply $H(t)=H_{S}(t)+H_{R}(t)$. From the fact that a single MVK-type hazard function with at most three piecewise-constant parameters is identifiable (Heidenreich et al., 1997), it follows directly that the 6-parameter CD2 model described is also identifiable in theory.

[Note: References cited in this Appendix appear above in the Reference Section of this report.] 


\section{Appendix 2}

\section{Estimated distributions of county GSDs of indoor radon concentrations}

LBNL Report No. 42820

1999

by Dr. Phillip Price

Completed under contract to LLNL for LLNL LDRD Project 97-ERD-050

(LLNL Technical Contact: Dr. K.T. Bogen) 


\title{
Estimated distribution of county GSDs of indoor radon concentrations.
}

\author{
Phillip Price \\ Lawrence Berkeley National Laboratory \\ Berkeley, CA 94720
}

\section{Introduction}

A long-standing goal of the radon research community has been to produce maps that somehow identify areas of elevated radon (e.g. Gundersen et al. 1993, Price et al. 1997, Cohen 1994, Alexander et al. 1993), where "elevated radon" is often somewhat vaguely defined but may include the arithmetic mean long-term indoor concentration in the area, or the geometric mean, or the fraction of homes exceeding some reference level such as the EPA's recommended action level of 4 picoCuries per liter ( $\mathrm{pCi} / \mathrm{L})$. The intent of such maps is often to identify areas for increased radon education, monitoring, and remediation, but sometimes radon maps (or, more generally, estimated radon distributions by area) are used for other purposes such as epidemiological modeling (Bogen 1997, Lubin and Steindorf 1995, Cohen 1995) or for analyzing costs and benefits of radon monitoring strategies (Lin et al, 1999).

Indoor radon measurements within counties are nearly lognormally distributed, so most quantitative predictions of radon distributions attempt to determine the geometric mean (GM) and geometric standard deviation (GSD) of measurements by county. Observed GSDs tend not to be highly variable compared to the GMs, and variables that are predictive of GMs have not been found to help predict GSDs; consequently, it is common to assume that county GSDs are identical, or that they only vary slightly. However, there is a possibility that some counties have unusually elevated GSDs, and thus have a large fraction of highradon homes even if their GM concentrations are fairly low. Knowledge of the distribution of county GSDs is thus necessary in order to determine the effectiveness of mean-based 
radon mapping methods.

Furthermore, predicted radon-related cancer rates in nonlinear radiation-risk models depend not only on arithmetic mean concentrations, but also on the distribution of radon exposures across the population (Bogen 1997), so variation in GSDs is a potentially important complicating factor in fitting such models. For example, a model that attempts to predict county lung cancer death rates as a funclion of indoor radon concentration, and that assumes that the entire county population is exposed to the county's arithmetic mean concentration, will substantially misclassify many or most individuals in the county. An example is presented in Appendix I, where we consider the number of households whose radon concentration falls into various concentration range bins, as a function of the county arithmetic mean, for several values of county GSD.

A complication in characterizing the radon distribution within counties is that most radon measurements are short-term measurements, usually made on the lowest level of the home (often an unoccupicd basement). Such measurements are known as "screening" measurements, and they are both biased and "noisy" compared to annual-average living-area measurements. The bias can be removed, given presently available short- and long-term data (White et al. 1990, Price and Nero 1996), but the existing data are not adequate for precisely estimating the excess variability of short-term measurements. Moreover, such excess variability probably varies by season and location. In short, there is no known way to use the variability of screening measurements within areas (such as counties) to estimate the variability of long-term living-area concentrations.

However, there is one high-quality database of long-term living-area radon measurements that is suitable for quantifying the within-county variation of indoor radon concentrations: the National Residential Radon Survey (NRRS) made radon measurements in about 5700 homes selected through a stratified random sampling scheme that sampled a total of 125 counties across the U.S. (Lucas et al. 1992). In this paper, we present the results from fitting these data with a statistical model that estimates both the within-county and within-censusblock variation of indoor radon concentrations, and also quantifies the extent to which the variability itself varies among counties and census blocks. 


\section{The Data}

The NRRS protocol used an alpha-track radon detector on every occupied level of the house, with a measurement time of 1 year, to calculate a "household mean" radon concentrationthe arithmetic mean of the radon measurements on all occupied levels. Weighting by occupancy time was not used, so that if $80 \%$ of the inhabitants' time was spent on one level of the home, while only $20 \%$ was spent on another level, the household mean measurement does not reflect this disparity. Still, this is the only large-scale random-sample survey that monitored on every occupied level of the home, and as such it is certainly the best survey for estimating parameters related to actual indoor exposures.

The survey also recorded a large variety of features of each home, such as the number of appliances vented to the outdoors, the type of heating and cooling system, and so on. Although such information has been used to produce predictive radon models, we do not use it in the present work, which is involved in characterizing radon distributions rather than in trying to locate high- or low-radon areas.

An important complicating factor in the survey is that a stratification scheme was used to oversample expected high-radon areas; furthermore, population weighting was used so that highly populous counties werc more likely to be selected than sparsely populated ones. Sampling weights were calculated as part of the original survey.

\subsection{Components of variation}

The NRRS selccted 125 counties through a stratified random sampling scheme. Within each county, exactly eight census blocks were selected (also via a stratified sampling scheme), and a small number of homes was selected in each block. The survey attempted to monitor every one of those homes.

The stratification scheme must be considered when estimating the GSDs and their uncertainties, since there is the possibility of missing very variable (or very uniform) census blocks within a county, and since only eight census blocks are sampled within each county so that inclusion of one census block with very high (or low) GM may also affect the estimated GSD. To get a feel for the magnitude of the components of variability, we plot observed radon measurements in Figure 1 for eight of the counties in EPA's Region III (the mid-Atlantic states). Each thin vertical column contains the measurements from one census 
block, and the blocks are divided into their counties by the vertical bars. Measurements are plotted on a log scale using a number identifying the county (using the 'primary sampling unit' identifier from the NRRS data). Note that some census blocks are more variable than others within the same county (particularly noticeable in the rightmost county). This illustrates that some census blocks are more variable than others (in log space).

In county 26 (sixth from the left) most of the census blocks have about the same mean radon level, whereas in county 25 (seventh from the left) there appears to be substantial variation. This illustrates that some counties have higher between-census-block variation than others (in log space).

It is apparent, given the large variation within census blocks and the small number of observations in each block, that the parameters associated with any individual census block can only be poorly estimated. Indeed, even the county parameters are not well estimated from these data-for example, county 24 (fifth from the left) has one sampled census block with much higher radon measurements than the others in the county, containing about $1 / 4$ of the measurements in the county. Are $1 / 4$ of the homes in the county really that high, or is it even higher, or much lower? Small-sample noise obviously creates substantial uncertainty in the parameters describing individual counties, although this uncertainty can be captured with an appropriate statistical model.

\subsection{Sensitivity to measurement error.}

Like all measurements, the alpha-track radon measurements were subject to error. Of particular concern for the present study is the effect of background subtraction on the GSD estimates by county. Background subtraction is necessary because even unexposed alphatrack detectors show some damage that is interpreted as raw counts of radiation exposure. To remove this spurious effect, an expected number of background counts is subtracted from the observed radon count for the detectors. However, random variation ensures that sometimes this expected background level will overestimate the actual background, while at other times it will underestimate it. In cases where the actual radon concentration is quite low, subtracting an overestimate of the background count can lead to a physically impossible (and meaningless) negative radon measurement. Moreover, because of the "regression effect", most of the very low radon measurements (say, less than $0.3 \mathrm{pCi} / \mathrm{L}$ household mean concentration) are underestimates of the true annual-averagc concentration. The influence 
Figure 1. "Flyspeck" plot of observed radon measurements in eight counties in Region III (the mid-Atlantic states). Each wide vertical bin contains the data from one county. Within each county, a different column contains the data from a census block. Each point (plotted by a number indicating the county, using the identifier in the NRRS data) represents the radon measurement in a home. The $y$ axis is logarithmic.

Some census blocks are much more variable than others; e.g., see county 29. (the last column)---one census block has very little variation in measurements compared to the others.

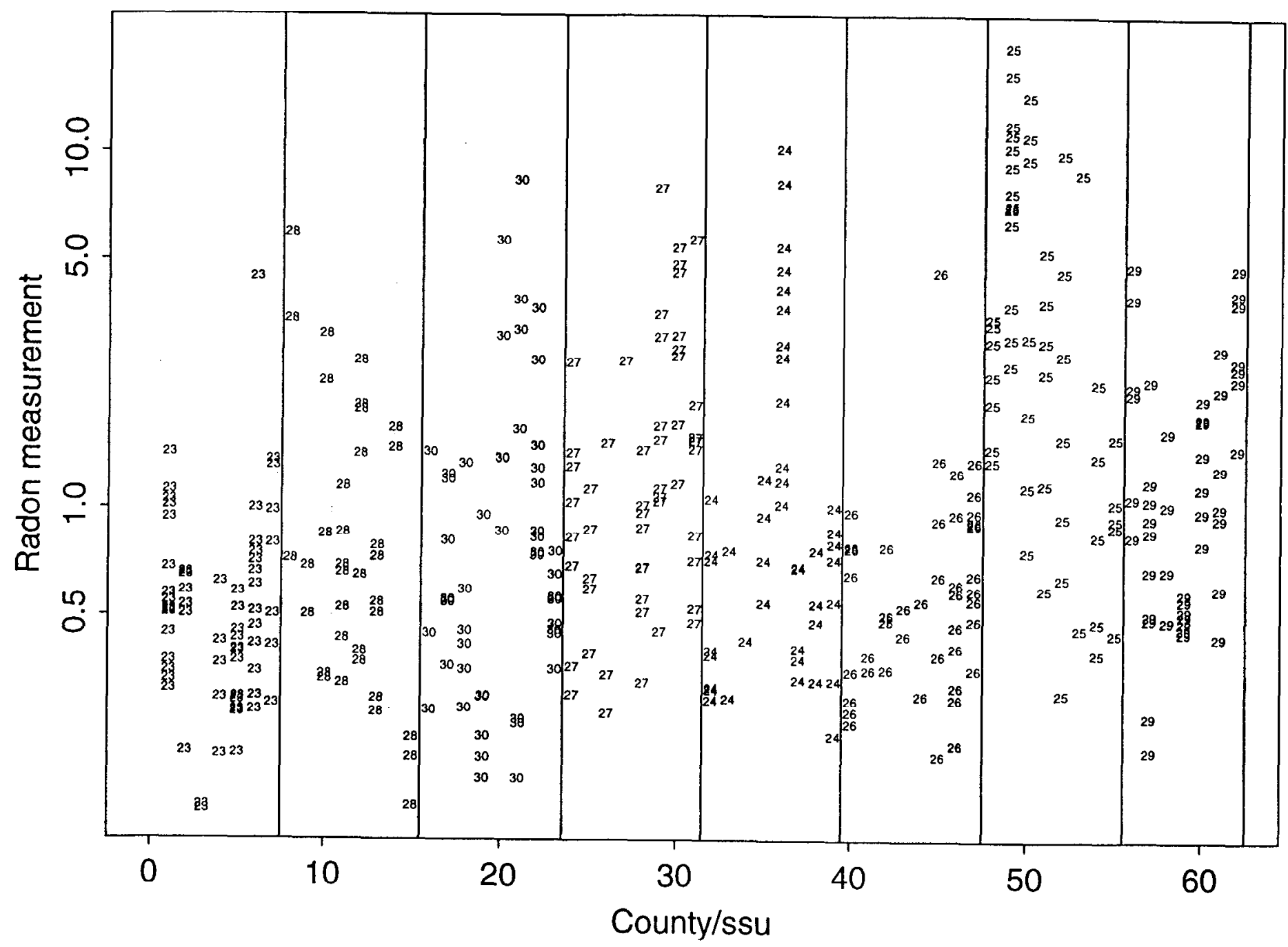


of the background subtraction effect diminishes with higher radon concentrations, since the effect is of the order of $\pm 0.1 \mathrm{pCi} / \mathrm{L}$, which becomes a trivial adjustment for measurements over 1 or $1.5 \mathrm{pCi} / \mathrm{L}$.

Still, when estimating the GSDs (by county, or by census block) it is necessary to handle the extremely low measurements somehow. Discarding them altogether is statistically invalid, since they really do represent homes with low radon levels. For calculating GMs and GSDs of observed data, one can use the maximum likelihood method with an appropriate lower limit of 0.2 or $0.3 \mathrm{pCi} / \mathrm{L}$, but the results can still depend on where this lower limit is set; additionally, such a method is inconsistent with complete modelling of the radon distribution. A better approach would be to include the background subtraction effect in the model, but the model would then be vastly more complicated.

In this work, we apply a slight adjustment to the radon measurements: we replace each radon measurement $r$ with $r^{\prime}=r / 2+\sqrt{r^{2} / 4+D}$, with $D=0.15 \mathrm{pCi} / \mathrm{L}$. This transformation has little effect on values of $r$ above about 0.5 or $0.75 \mathrm{pCi} / \mathrm{L}$ (leading to transformed values of 0.54 and $0.78 \mathrm{pCi} / \mathrm{L}$, respectively), but yields transformed radon concentrations above 0 in all cases; moreover, the resulting distribution of transformed radon measurements within each region is nearly lognormal. However, this equation is merely a convenient ad hoc adjustment, and does not necessarily bring the measurements into line with reality.

Unfortunately, the results in the present paper are somewhat sensitive to the details of this procedure, most notably in regions with many very low household mean radon measurements: Regions $1,6,9$, and 10 , in all of which $18 \%$ or more of the reported measurements are less than $0.3 \mathrm{pCi} / \mathrm{L}$. For example, in one of the census blocks in Region 1 (New England), 3 of the 5 reported mean concentrations are below $0.3 \mathrm{pCi} / \mathrm{L}$, although none are below 0.1 . The sampling GSD of the observed data is 2.08 , but the GSD of the transformed data (transformed as above) is 1.48 , and if $\mathrm{D}=0.1 \mathrm{pCi} / \mathrm{L}$ were used as the adjustment rather than $0.15 \mathrm{pCi} / \mathrm{L}$, then the GSD of the transformed data would be 1.62 .

In short, given the shortcomings of the data it is difficult to estimate the actual GSDs for areas in which many of the radon measurements are very low. 


\section{The Model}

\subsection{Model definition}

The NRRS data are stratified, and this stratification must be accounted for in estimating the county GSDs. After some preliminary investigations, it was clear that a realistic statistical model of the NRRS measurements must include several components of variation: the individual-house measurements are more variable in some census blocks than in others, and the census block GMs more variable in some counties than in others.

Let $y_{i j k}$ be the $\log$ measurement in home $k$, in census block $j$ of county $i$. We will denote the vector of $\left\{y_{i j}\right\}$ values with $y$, and likewise will denote the vector of any of the following parameters by dropping the subscripts.

We assume that the house-to-house variance within a census block, $\delta_{i j}^{2}$, varies from one census block to the next:

$$
y_{i j k} \sim \mathrm{N}\left(\theta_{i}+\phi_{i j}, \delta_{i j}^{2}\right)
$$

where $\theta_{i}$ is the county effect for county $i$ and $\phi_{i j}$ is the census block effect for block $j$ in county $i$.

We further assume that the county effects are normally distributed about some grand mean $\mu$ :

$$
\theta_{k} \sim \mathrm{N}\left(\mu, \tau^{2}\right)
$$

and that the census block effects are normally distributed about zero, with the variance in census block effect itself varying among counties:

$$
\phi_{i j} \sim \mathrm{N}\left(0, \sigma_{i}^{2}\right)
$$

We further assume that the variances are drawn from distributions

$$
\sigma_{i j}^{2} \sim \operatorname{Inv}-\chi^{2}\left(\nu_{\sigma}, \sigma_{0}^{2}\right)
$$

and

$$
\delta_{i j}^{2} \sim \operatorname{Inv}-\chi^{2}\left(\nu_{\delta}, \delta_{0}^{2}\right)
$$

with $1 / \nu_{\sigma}$ and $1 / \nu_{\delta}$ given flat (uniform) prior distributions from 0 to infinity. 


\section{$3.2 \quad$ Fitting the model}

The model was fit with a combination of alternating conditional sampling (also known as the Gibbs Sampler) and Metropolis Monte Carlo methods, as described in Gelman et al. (1995).

Ignoring the Metropolis steps for the moment, the Gibbs Sampler holds all of the parameters fixed except for one, and draws a candidate value of that parameter from the sampling distribution conditional on the values of all of the other parameters (plus the data). Thus it is necessary to work out the conditional distribution of each parameter, given the other parameters and the data. For notational simplicity, we introduce notation so that $\gamma$ represents the entire set of data and parameters in the model: $\{y\}, \mu, \tau,\{\sigma\},\{\phi\},\{\delta\}, \nu_{\sigma}, \nu_{\delta}, \sigma_{0}, \delta_{0}$, with a bracketcd symbol following $\gamma$ denoting all of the parameters except the subscripted one. The resulting equations for each parameter are (from application of Bayes's theorem): For the county and block effects,

$$
\phi_{i j} \mid \gamma[\phi] \sim \mathrm{N}\left(\frac{\sum_{k}\left(y_{i j k}-\theta_{i}\right) / \delta_{i j}^{2}}{1 / \sigma_{i}^{2}+n_{i j} / \delta_{i j}^{2}}, \frac{1}{1 / \sigma_{i}^{2}+n_{i j} / \delta_{i j}^{2}}\right),
$$

and

$$
\theta_{i} \mid \gamma[\theta] \sim \mathrm{N}\left(\frac{\mu / \tau^{2}+\sum_{j} n_{i j}\left(\bar{y}-\phi_{i j}\right) / \delta_{i j}^{2}}{1 / \tau^{2}+\sum_{j} n_{i j} / \delta_{i j}^{2}}, \frac{1}{1 / \tau^{2}+\sum_{j} n_{i j} / \delta_{i j}^{2}}\right)
$$

The conditional distributions of $\delta_{i j}^{2}$ and $\sigma_{i j}^{2}$ are scaled-inverse- $\chi^{2}$ :

$$
\delta_{i j}^{2} \mid \gamma[\delta] \sim \operatorname{Inv}-\chi^{2}\left(\nu_{\delta}+n_{i j}, \frac{\nu_{\delta} \delta_{0}+\sum_{k} y_{i j k}-\left(\theta_{i}+\phi_{i j}\right)}{\nu_{\delta}+n_{i j}}\right)
$$

and

$$
\sigma_{i}^{2} \mid \gamma[\sigma] \sim \operatorname{Inv}-\chi^{2}\left(\nu_{\sigma}+n p_{i}, \frac{\nu_{\sigma} \sigma_{0}^{2}+\sum_{j} \phi_{i j}}{\nu_{\sigma}+n p_{i}}\right)
$$

where $n p_{i}$ is the number of secondary sampling units in county $i$.

Finally, the distributions of $\delta_{0}$ and $\sigma_{0}$ are Gamma:

$$
\sigma_{0} \mid \gamma\left[\sigma_{0}\right] \sim \Gamma\left(\frac{n_{\theta} \nu_{\sigma}}{2}+1, \sum_{i} \frac{\nu_{s} i g m a}{2 \sigma_{i}^{2}}\right)
$$

and

$$
\delta_{0} \mid \gamma\left[\text { delta }_{0}\right] \sim \Gamma\left(\frac{n_{\delta} n u_{\delta}}{2}+1, \sum_{i j} \frac{n u_{\delta}}{2 \delta_{i j}^{2}}\right) .
$$

Note that the model defined above does take account of the stratification structure of the data, but does not include the over- and under-sampling of some areas. Taking account 
of the stratification would be necessary if we were analyzing GMs, but investigation (using both ordinary and Bayesian regressions) shows no correlation between GSDs and sampling weights, although there is a correlation between GMs and sampling weights). Areas that were more likely to be sampled have neither higher nor lower GSDs than areas that were less likely to be sampled.

\section{Results}

Before discussing the results, we caution the reader that an unusual amount of attention is required in order to understand what is being said in this section. Recall that the overall goal is not to try to characterize the within-county variability of radon (that is, we are not trying to estimate a GSD within a county), rather we are trying to characterize the distribution of GSDs, or to put it another way, to characterize the variability of the withincounty variability. Already this can be confusing, but we are also compelled to discuss the uncertainty in the distribution of variabilities. This presents some challenge in terms of clarity of exposition.

Starting from the most understandable level: the results of the analysis do include estimates (and uncertainties) of the variances for each of the individual census blocks and counties in the NRRS data; however, as these constitute a total of only 125 of the 3000 U.S. counties, and only eight of the census blocks within each county, these particular parameters are not particularly informative. More importantly, the analysis estimates the so-called "hyperparameters" describing the overall distribution of variances between census blocks and between homes within census blocks. The situation is somewhat analogous to using the NRRS data to estimate the distribution of houschold radon concentrations in the U.S.- the geometric mean, geometric standard deviation, etc., can be determined for the whole U.S. and for individual regions, but this knowledge does not tell us which U.S. counties have elevated or depressed radon levels. Similarly, the present analysis tells us the distribution of county GSDs, but does not tell us which GSDs are high and which are low (except for those included in the data, of course).

Table 4 shows central parameter estimates for each region. The Monte Carlo method used to estimate the parameters generates many estimates (we used 8000 Monte Carlo steps) for each parameter; the table shows the median value of the hyperparameters describing the within-county variability, as well as the implied 50\% range of county GSD's. For instance, 
Table 1: Central estimates of parameter values, by region.

\begin{tabular}{|lrrrr|rrrrr|}
\hline & median & median & median & median & \multicolumn{5}{|c}{ est. percentiles of GSD dist. } \\
Region & $\sigma_{0}^{2}$ & $\nu_{\sigma}$ & $\delta_{0}^{2}$ & $\nu_{\delta}$ & 10 & 25 & 50 & 75 & 90 \\
\hline I & 0.453 & 29 & 0.500 & 31 & 2.53 & 2.61 & 2.71 & 2.82 & 2.95 \\
II & 0.288 & 34 & 0.401 & 17 & 2.28 & 2.32 & 2.38 & 2.45 & 2.58 \\
III & 0.226 & 54 & 0.316 & 7 & 2.20 & 2.23 & 2.27 & 2.31 & 2.36 \\
IV & 0.187 & 17 & 0.405 & 21 & 2.14 & 2.17 & 2.24 & 2.30 & 2.40 \\
V & 0.219 & 21 & 0.361 & 26 & 2.10 & 2.14 & 2.20 & 2.28 & 2.35 \\
VI & 0.266 & 22 & 0.324 & 16 & 2.11 & 2.17 & 2.23 & 2.32 & 2.45 \\
VII & 0.201 & 17 & 0.365 & 24 & 2.08 & 2.14 & 2.19 & 2.27 & 2.37 \\
VIII & 0.218 & 47 & 0.326 & 12 & 2.12 & 2.14 & 2.18 & 2.23 & 2.27 \\
IX & 0.135 & 51 & 0.209 & 10 & 1.83 & 1.86 & 1.89 & 1.92 & 1.95 \\
X & 0.230 & 39 & 0.298 & 24 & 2.03 & 2.07 & 2.11 & 2.17 & 2.21 \\
\hline
\end{tabular}

for Region I (New England), the median estimate of $\sigma_{0}^{2}$ is 0.325 , and the median estimate of $\nu_{\sigma}$ is 65. If these estimates are accurate, then (conditional on the model, of course) most counties in New England have about the same between-census-block variability - 65 degrees of freedom is a fairly large number in the scaled inverse-chi-squared distribution. The lower estimate of $\nu_{\delta}, 31$, implies that some census blocks have more between-house variability than others do. The combination of the estimated variation in between-house variability and the estimated variation in between-block variability yields estimates of the variation in the GSDs within this region: as the table indicates, if the central parameter estimates are correct then in EPA's Region I the median GSD is 2.71, and about 50\% of GSDs fall between 2.61 and 2.82 .

The uniformity of the GSD estimates across the entire U.S. is striking: almost all regions have median GSDs in the neighborhood of 2.2, and about half of the counties in the U.S. have GSDs between 2.15 and 2.35., with only regions I and IX deviating substantially from this pattern. Moreover, the partitioning of this variation into its components (within-block and between-block) is very similar across regions.

\subsection{Uncertainties in the distributional parameters}

Table 4 indicates only the central estimates of each parameter and the implied distribution of GSDs if these "best guess" values are actually true. But in fact, there is some uncertainty in some of the parameters $-\nu_{\sigma}$ and $\nu_{\delta}$ in particular. If the true values are actually substantially lower than the central estimates, then the distributions of between-block and between-home- 
within-block variances are wider, leading to more variability in county GSDs.

The most intuitive way to summarize the uncertainty in the distribution of GSDs is to consider how wide or narrow the distribution could be, given the uncertainties of the various parameters. For instance, in Region II we estimate that the 90th percentile of county GSDs is 2.58 , but of course the true 90th percentile could instead be higher or lower than this value. What is the range in which we are fairly certain that the 90 th percentile actually falls?

The uncertainties vary somewhat by region, but one standard error tends to be of the order of \pm 0.08 for the 10th and 25th percentile GSD, \pm 0.09 for the median, \pm 0.10 for the 75 th percentile, and \pm 0.15 for the 90 th percentile.

Actually the posterior distributions are not normal distributions, so that assuming normality doesn't quite give the right error bounds for a region containing $90 \%$ of the probability. For instance, the 10th percentile in Region II is almost certainly between 2.06 and 2.35 (the region containing the central $90 \%$ of probability), rather than between 2.02 and 2.37 as would obtain, given the standard error for the 10 th percentile of 0.87 in this region, if the posterior distribution were normal.

As indicated above, although the estimates are reasonably certain for the 10th percentile and the median GSD in each region, there is much more uncertainty in just how high the highest GSDs in a region could be - the uncertainty in the 90th percentile is really fairly large. For instance, we cannot completely rule out the possibility that the most variable $10 \%$ of the counties in Region II could have GSDs over 2.8: the estimated 90th percentile in that region is 2.58 , but with an uncertainty (one standard error) of \pm 0.15 .

It is worth noting that GSDs of short-term "screening" data tend to be much higher than these estimates of true living-area-average GSDs, with observed county GSDs over 3.0 being fairly common for screening data. It has of course long been recognized that screening measurements are more variable than annual-average living-area measurements, due to temporal variability, lack of spatial averaging within the house, and so on. Still, we are aware of several cases (unpublished) in which state departments of health have used screening GSDs in conjunction with estimated county GMs in order to estimate the fraction of homes with living-area concentrations over a threshold such as $4 \mathrm{pCi} / \mathrm{L}$. Since the screening GSDs tend to be much higher than the actual concentrations, this procedure will generally lead to a greatly elevated estimate of the fraction of homes exceeding the 
reference level.

\subsection{Model validation}

Even before seeing the results, one might suspect several shortcomings in the statistical model. For example, it seems reasonable to think that counties that show unusually large variation between census block means (that is, counties with large values of $\sigma_{i}$ ) might also show unusually large variation between homes within census blocks (that is, high values of $\left.\phi_{i j}\right)$.

The best way to include such a possibility would be to incorporate such a correlation in the model and explicitly estimate its magnitude. We have not done this. Instead, we fit the model without such a correlation, and examine the correlation between betweenand within-block variability in the posterior distributions. This is not quite right, and will generally lead to an underestimate of the correlation, but at least we would expect to scc gross effects if they were present. But in fact, there is no evidence of such an effect. To put it another way, any such effect then is small compared to the uncertainties in estimating it, since these uncertainties tend to be rather large. For a given county, some census blocks can be much more variable than others (the number of degrees of freedom $\nu_{\delta}$ is below 20 in most regions), and since only 8 census blocks were monitored in each county if some blocks show more internal variability than others it is hard to tell whether the entire county shares this feature, or whether one or two blocks with unusually high variability simply happened to be sampled (or, for that matter, whether the extra variability is simply due to smallsample variation within the block). Thus the correlation between within- and between-block variability is swamped by the uncertainties in the various parameters.

A more serious problem is revealed by posterior predictive checks. In a posterior prcdictive check, the model is fit to the data, and then the parameters of the model are used to create simulated data. These simulated data are then compared to the actual data. The process seems circular - won't the simulated data match the actual data perfectly, since the simulated data are based on the fit to the actual data? The answer is "no", because the model makes certain assumptions (normality, inverse-chi-squared distribution of variances, etc.), and if these assumptions are significantly violated then the simulated data will not agree with the observed data.

Unfortunately, this phenomenon actually occurs, notably for Regions I, II, and XI: 
when we simulate data from the models, there are some noticeable differences between the simulated data and the actual observations. In particular, in these regions the highest observed GSDs within individual census blocks are consistently somewhat higher (of the order of $10 \%$ higher) than expected based on simulating from the model. Note that all of these regions have a large fraction of homes with very low radon measurements. Since the observed GSDs (and, via the model, the simulated GSDs) are sensitive to details of how such low measurements are handled, it seems likely that the poor model fit in these regions is due to inadequate modelling of the background subtraction effect. Unfortunately, this implies that the GSD parameter estimates in these regions are unreliable. In particular, we suspect that the true GSDs in Region I are considerably lower than the model implies, and those in Region IX may be substantially higher.

Model fit is much better in other regions, and we have much more confidence in the estimates for the rest of the country.

\section{Conclusions}

In most regions of the U.S., almost all county GSDs or annual-average living-area radon concentrations fall between 2.1 and 2.4. Possible exceptions include Region I (New England) and Region IX (the Southwest), but a more likely explanation for the deviation of the estimates in those regions is a lack of model fit for very low concentration measurements, due to background substraction effects.

Both the within- and between-census-block variations are substantial. Even within a given census block, log-space variances tend to be about 0.3 to 0.4 , implying coefficients of variation of $\exp (\sqrt{0.3})=1.7$ to $\exp (\sqrt{0.4})=1.9$. Thus, even if a census block GM is exactly known, there is a large amount of variation between individual homes in the census block. The number of degrees of freedom in the distribution describing the census block GSDs is small, suggesting that some census blocks are much more variable than others. This is not surprising, since all census blocks contain about the same number of people (of the order of 200) and thus vary greatly in spatial extent, and one expects that spatially large census blocks will be considerably more variable than spatially small ones, which may encompass only a single city block. 


\section{References}

Alexander, B.; Rodman, N.; White, S.B.; Phillips, J. (1993). Areas of the United States with elevated screening levels of Rn222. Health Physics, 66, 50-54.

Bogen, K. T. (1997). Do U.S. county data disprove linear no-threshold predictions of lung cancer risk for residential radon? A preliminary assessment of biological plausibility. Human and Ecological Risk Assessment 3, 157-186.

Cohen, B. L. (1994). Indoor radon maps of the United States. Health Physics 66, 201-205.

Cohen, B. L. (1995). Test of the linear-no threshold theory of radiation carcinogenesis for inhaled radon. Health Physics 68, 157-174 .

Gundersen, L.C.; Otton, J. K.; Szarzi, S.L. EPA Region 3 Geologic Radon Potential Summary. In Geologic Radon Potential of EPA Region 3, USGS Open-File Report 93-292-C, R. Schumann editor. (1993).

Lin, C.Y.; Gelman, A.; Price, P.N.; Krantz, D.H. (1999) Analysis of local decisions using hierarchical modeling, applied to home radon measurement and remediation. Accepted by Statistical Science, to appear.

Lucas, R.M.; Grillo, R.B.; Perez-Michael, A.; Kemp, S.S. Final Report: National Residential Radon Survey Statistical Analysis. Research Triangle Institute. For the U.S. Environmental Protection Agency, Washington, D.C.; 1992.

Lubin, J.H., and Steindorf, K. (1995) Cigarette use and the estimation of lung cancer attributable to radon in the United States, Radiation Research 141, 79-85.

Price, P. N., and Nero, A. V. (1996). Joint analysis of long- and short-term radon monitoring data from the Northern U.S. Environment International 22, Suppl. 1, S699-S714.

Price, P. N. (1997). Predictions and maps of county mean indoor radon concentrations in the Mid-Atlantic States. Health Physics 72, 893-906.

White, S. B., Clayton, G. A., Alexander, B. V., and Clifford, M. A. (1990). A statistical analysis: Predicting annual Rn-222 concentration from 2-day screening tests. In Proceedings of the 1990 Symposium on Radon and Radon Reduction Technology 1, 3-117-3-118. Washington, D.C: U.S. EPA.

White, S. B, Bergsten, J. W., Alexander, B. V., Rodman, N. F., and Phillips, J. L. (1992). Indoor Rn222 concentrations in a probability sample of 43000 houses across 30 states. 
Health Physics 62, 41-50.

\section{A Relationship between GM/GSD and "exposure bins".}

Suppose counties are grouped into "exposure bins" based on geometric mean concentration. The individual homes in a given county will have radon concentrations that vary substantially about the GM, so although the county is in a particular bin the homes will be apportioned among all of the bins. Table 2 shows the fraction of homes in each of six bins, as a function of county GM, assuming a county GSD of 2.2. The bins used here are those used in Bogen (1992) in fitting a nonlinear dose-response model to lung cancer mortality data and radon measurements.

\section{B Fraction of homes over $4 \mathrm{pCi} / \mathrm{L}$, for various GMs and GSDs}

The fraction of homes exceeding the EPA's recommended action level of $4 \mathrm{pCi} / \mathrm{L}$ naturally varies as a function of GM and GSD (see table 3). Almost all county GSDs fall between 2.0 and 2.6, with most closer to the center of this range. The fraction of homes exceeding $4 \mathrm{pCi} / \mathrm{L}$ shows large relative variation (but small absolute variation) as a function of GSD when the GM is low; for higher values of GM, the relative variation is fairly small as a function of GSD-indeed, when the GM is exactly $4.0 \mathrm{pCi} / \mathrm{L}$, the fraction of homes over $4 \mathrm{pCi} / \mathrm{L}$ is always 0.5 , independent of the GSD. For practical purposes, the variation as a function of GSD is most important for GMs between 1.5 and 2.0: for counties with GMs under $1.5 \mathrm{pCi} / \mathrm{L}$, under $10 \%$ of homes exceed $4 \mathrm{pCi} / \mathrm{L}$ so these counties would not likely be the focus of detailed study, whereas for homes over $2 \mathrm{pCi} / \mathrm{L}$, over $20 \%$ of homes exceed 4 $\mathrm{pCi} / \mathrm{L}$ so these counties are "at risk" no matter what the GSD. Only in the intermediate range can the GSD be the deciding factor in whether the county merits special attention based on the fraction of homes over $4 \mathrm{pCi} / \mathrm{L}$. 
Table 2: Fraction of homes in each exposure bin, as a function of county GM, assuming a county GSD of 2.2 and using the same bins as Bogen (1992). Horizontal lines separate GM regions in which different bins have a plurality of the homes. Note that for this GSD and these bins, the fifth bin never has a plurality. The GM increments by 0.2 for GM values above $2.4 \mathrm{pCi} / \mathrm{L}$.

\begin{tabular}{|c|c|c|c|c|c|c|}
\hline $\begin{array}{r}\mathrm{GM} \\
\mathrm{pCi} / \mathrm{L} \\
\end{array}$ & $\begin{array}{r}<0.394 \\
\mathrm{pCi} / \mathrm{L}\end{array}$ & $\begin{array}{r}0.394-0.787 \\
\mathrm{pCi} / \mathrm{L} \\
\end{array}$ & $\begin{array}{r}0.787-1.38 \\
\mathrm{pCi} / \mathrm{L}\end{array}$ & $\begin{array}{r}1.38-2.17 \\
\mathrm{pCi} / \mathrm{L}\end{array}$ & $\begin{array}{r}2.17-3.15 \\
\mathrm{pCi} / \mathrm{L} \\
\end{array}$ & $\begin{array}{l}>3.15 \\
\mathrm{pCi} / \mathrm{L}\end{array}$ \\
\hline 0.1 & 0.959 & 0.037 & 0.004 & 0.000 & 0.000 & 0.000 \\
\hline 0.2 & 0.805 & 0.154 & 0.034 & 0.006 & 0.001 & 0.000 \\
\hline 0.3 & 0.635 & 0.254 & 0.084 & 0.020 & 0.005 & 0.001 \\
\hline 0.4 & 0.492 & 0.312 & 0.137 & 0.042 & 0.012 & 0.004 \\
\hline 0.5 & 0.381 & 0.336 & 0.184 & 0.068 & 0.022 & 0.010 \\
\hline 0.6 & 0.297 & 0.338 & 0.220 & 0.094 & 0.034 & 0.018 \\
\hline 0.7 & 0.233 & 0.326 & 0.246 & 0.119 & 0.047 & 0.028 \\
\hline 0.8 & 0.185 & 0.307 & 0.264 & 0.142 & 0.062 & 0.041 \\
\hline 0.9 & 0.147 & 0.285 & 0.274 & 0.162 & 0.076 & 0.056 \\
\hline 1.0 & 0.119 & 0.262 & 0.278 & 0.179 & 0.090 & $0 . \overline{073}$ \\
\hline 1.1 & 0.096 & 0.239 & 0.278 & 0.192 & 0.103 & 0.091 \\
\hline 1.2 & 0.079 & 0.217 & 0.274 & 0.203 & 0.116 & 0.110 \\
\hline 1.3 & 0.065 & 0.197 & 0.268 & 0.212 & 0.127 & 0.131 \\
\hline 1.4 & 0.054 & 0.179 & 0.260 & 0.218 & 0.137 & 0.152 \\
\hline 1.5 & 0.045 & 0.162 & 0.251 & 0.222 & 0.146 & 0.173 \\
\hline 1.6 & 0.038 & 0.146 & 0.242 & 0.225 & 0.154 & 0.195 \\
\hline 1.7 & 0.032 & 0.132 & 0.231 & 0.226 & 0.161 & 0.217 \\
\hline 1.8 & 0.027 & 0.120 & 0.221 & 0.226 & 0.167 & 0.239 \\
\hline 1.9 & 0.023 & 0.109 & 0.211 & 0.224 & 0.172 & 0.261 \\
\hline 2.0 & 0.020 & 0.099 & 0.201 & 0.222 & 0.177 & 0.282 \\
\hline 2.1 & 0.017 & 0.090 & 0.191 & 0.219 & 0.180 & 0.304 \\
\hline 2.2 & 0.015 & 0.082 & 0.181 & 0.216 & 0.182 & 0.324 \\
\hline 2.3 & 0.013 & 0.074 & 0.172 & 0.212 & 0.184 & 0.345 \\
\hline 2.4 & 0.011 & 0.068 & 0.163 & 0.208 & 0.186 & 0.365 \\
\hline 2.6 & 0.008 & 0.056 & 0.146 & 0.198 & 0.187 & 0.404 \\
\hline 2.8 & 0.006 & 0.047 & 0.131 & 0.188 & 0.186 & 0.441 \\
\hline 3.0 & 0.005 & 0.040 & 0.118 & 0.178 & 0.184 & 0.475 \\
\hline 3.2 & 0.004 & 0.034 & 0.105 & 0.168 & 0.181 & 0.508 \\
\hline 3.4 & 0.003 & 0.029 & 0.095 & 0.158 & 0.177 & 0.539 \\
\hline 3.6 & 0.003 & 0.024 & 0.085 & 0.148 & 0.172 & 0.567 \\
\hline 3.8 & 0.002 & 0.021 & 0.077 & 0.139 & 0.167 & 0.594 \\
\hline 4.0 & 0.002 & 0.018 & 0.069 & 0.130 & 0.162 & 0.619 \\
\hline
\end{tabular}


Table 3: Fraction of homes exceeding $4 \mathrm{pCi} / \mathrm{L}$, for various values of $\mathrm{GM}$ and GSD

\begin{tabular}{|r|r||rrrr|}
\hline & \multicolumn{1}{|l||}{} & \multicolumn{4}{c|}{ GSD } \\
& & 2.0 & 2.2 & 2.4 & 2.6 \\
\hline & 0.5 & 0.001 & 0.004 & 0.009 & 0.015 \\
& 1.0 & 0.023 & 0.039 & 0.057 & 0.073 \\
& 1.5 & 0.079 & 0.107 & 0.131 & 0.152 \\
GM & 2.0 & 0.159 & 0.190 & 0.214 & 0.234 \\
& 2.5 & 0.249 & 0.276 & 0.296 & 0.311 \\
& 3.0 & 0.339 & 0.358 & 0.371 & 0.382 \\
& 3.5 & 0.424 & 0.433 & 0.439 & 0.444 \\
\hline
\end{tabular}




\section{Computer code for estimating the parameters}

The following is computer code, in the " $\mathrm{S}$ " programming language, that was used to calculate the parameter estimates in this paper. Portions of the code will probably be understandable to anyone with programming experience, but some knowledge of $\mathrm{S}$ is needed to really make sense of it. One important note is that $S$ is vector-oriented, so that for instance "phi" is an entire vector of values, and "ybar" is a vector of values; "ybar - phi" is a vector containing the componentwise difference between ybar and phi.

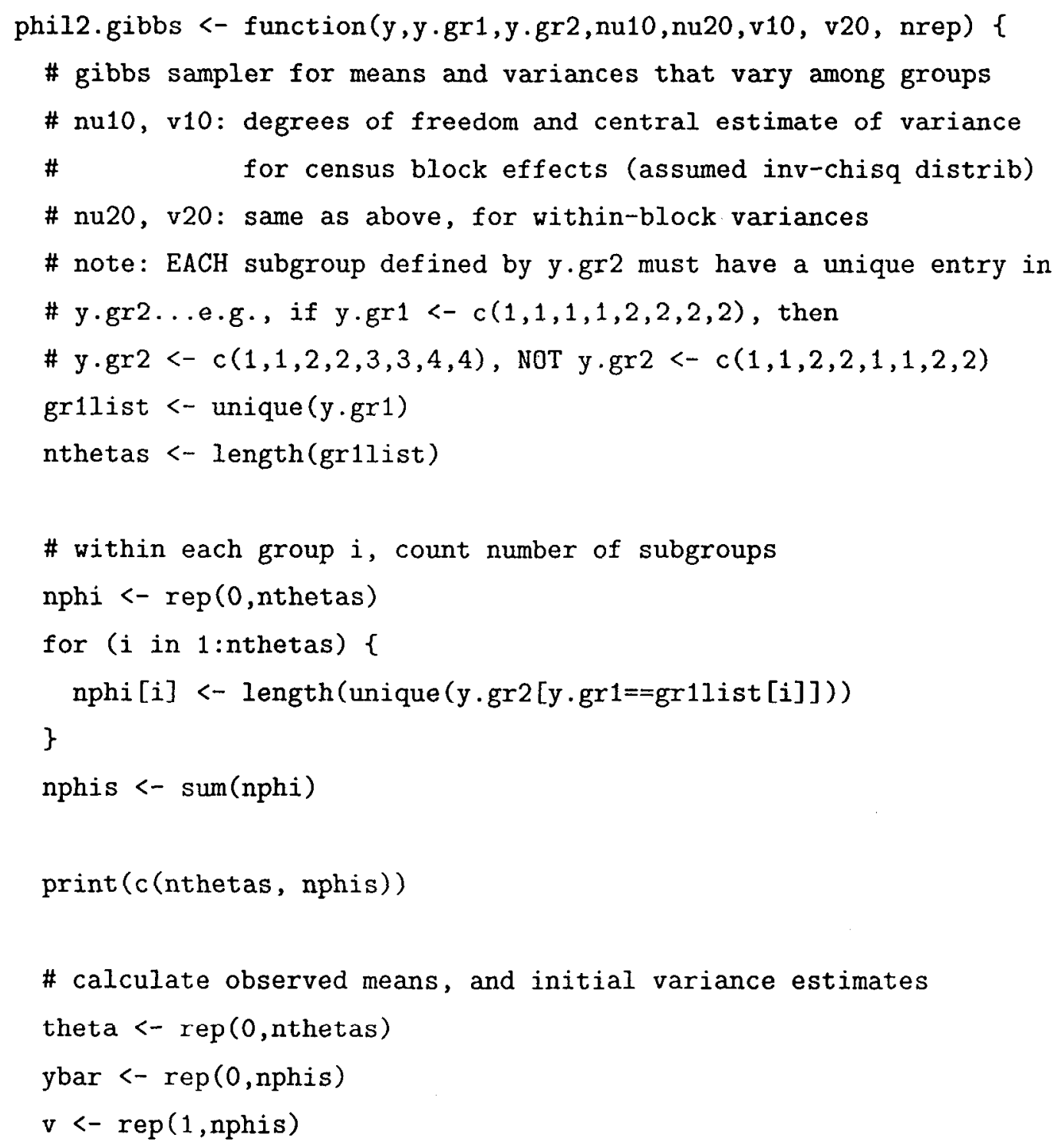




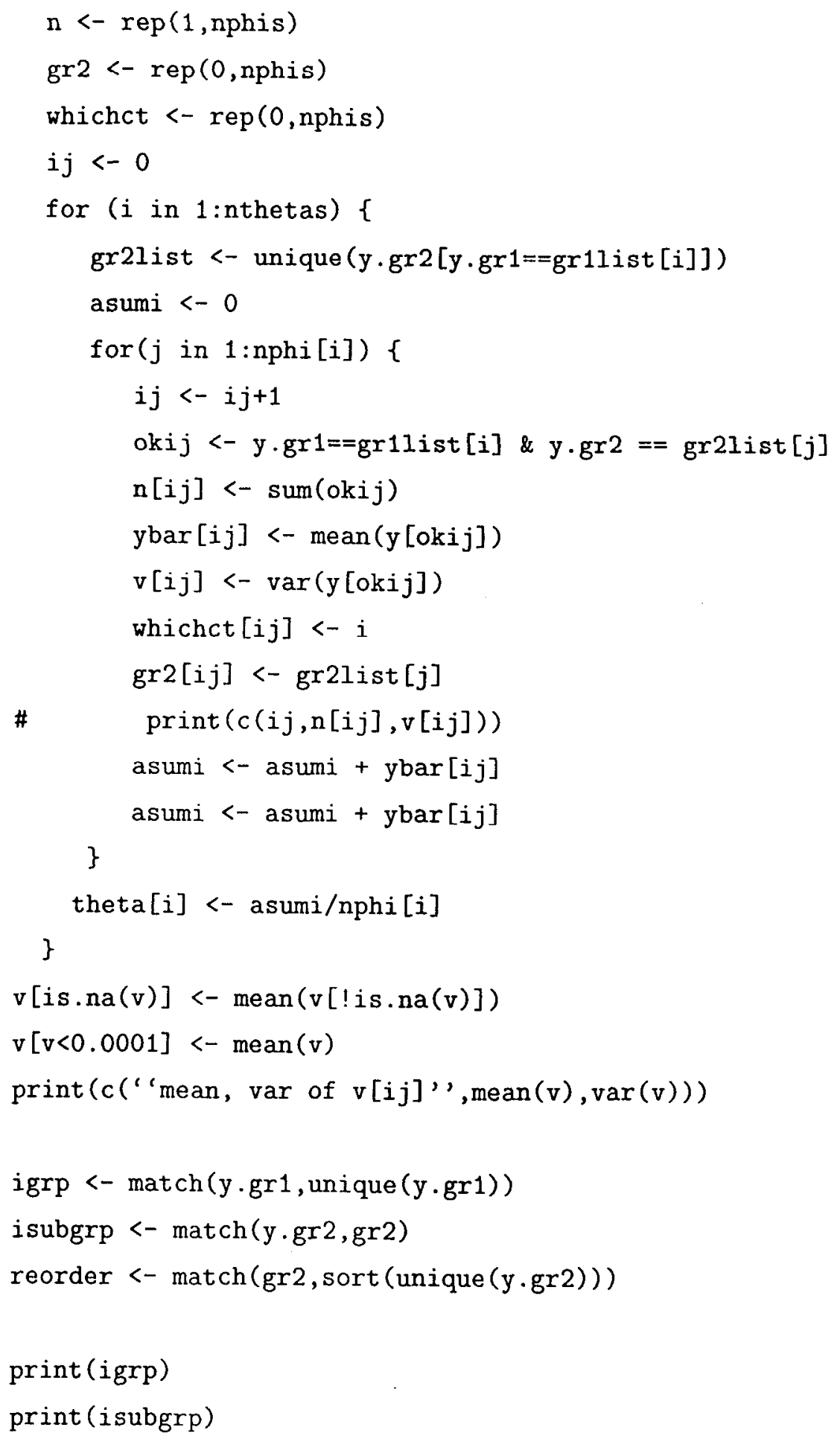




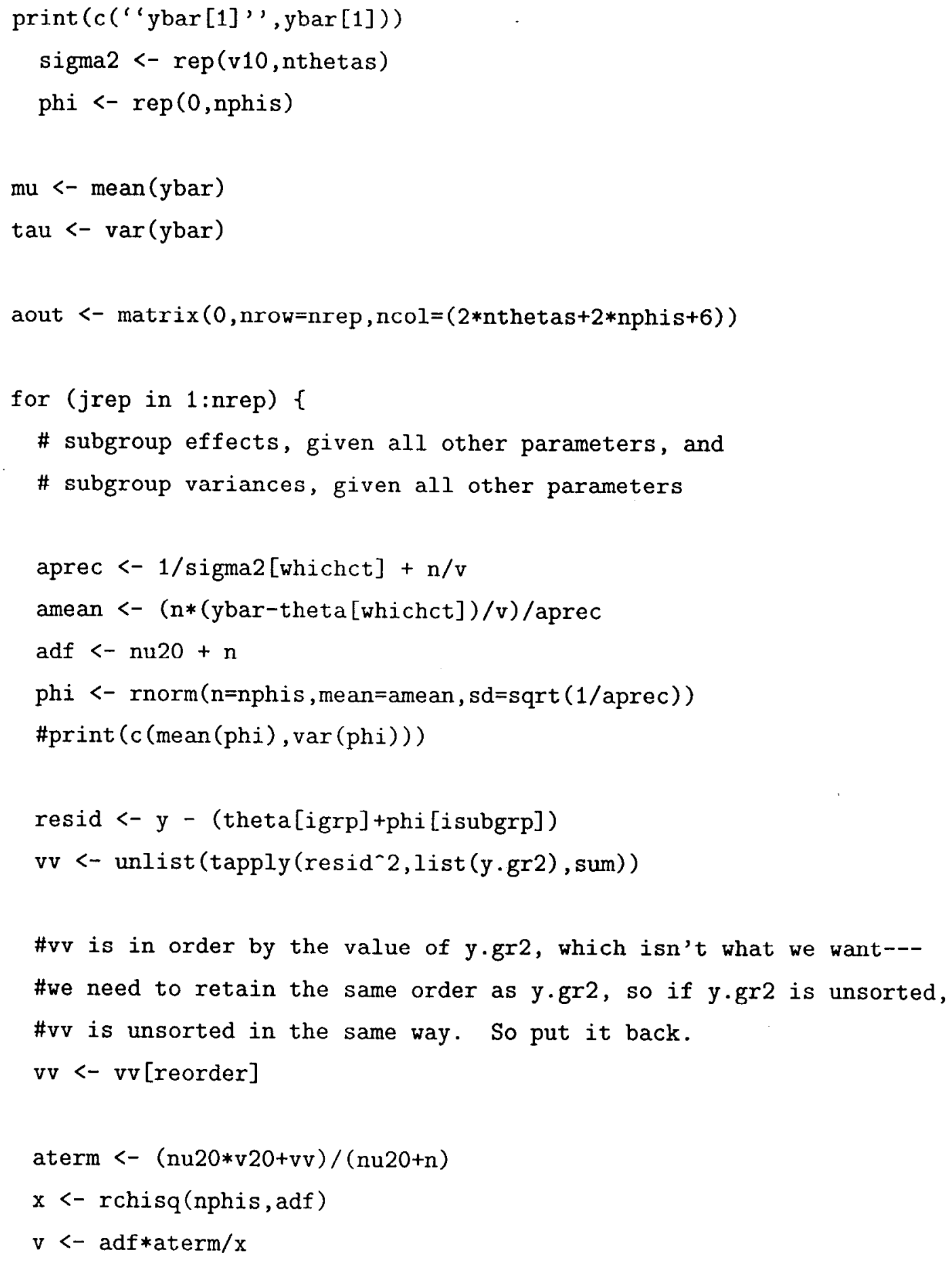




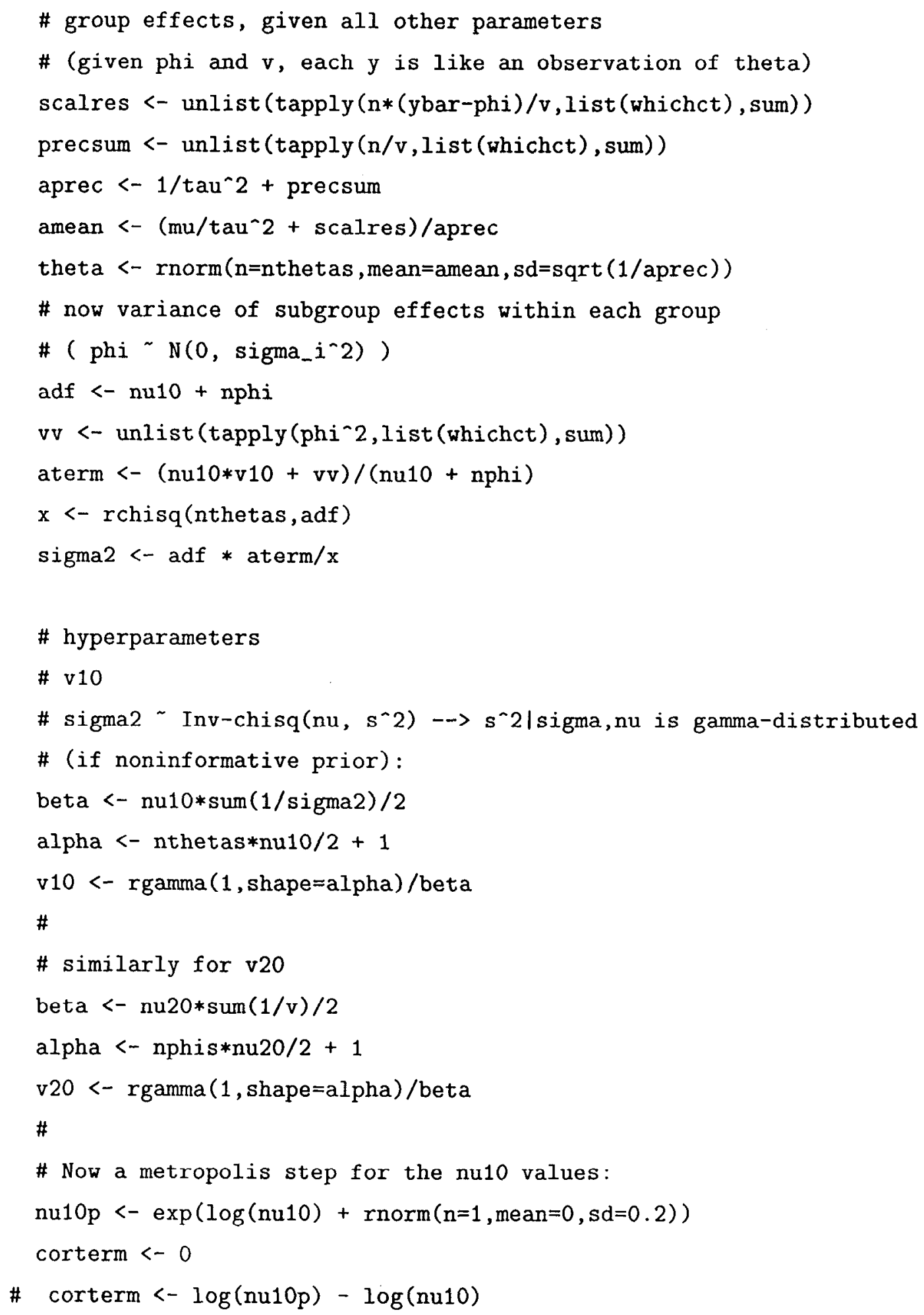




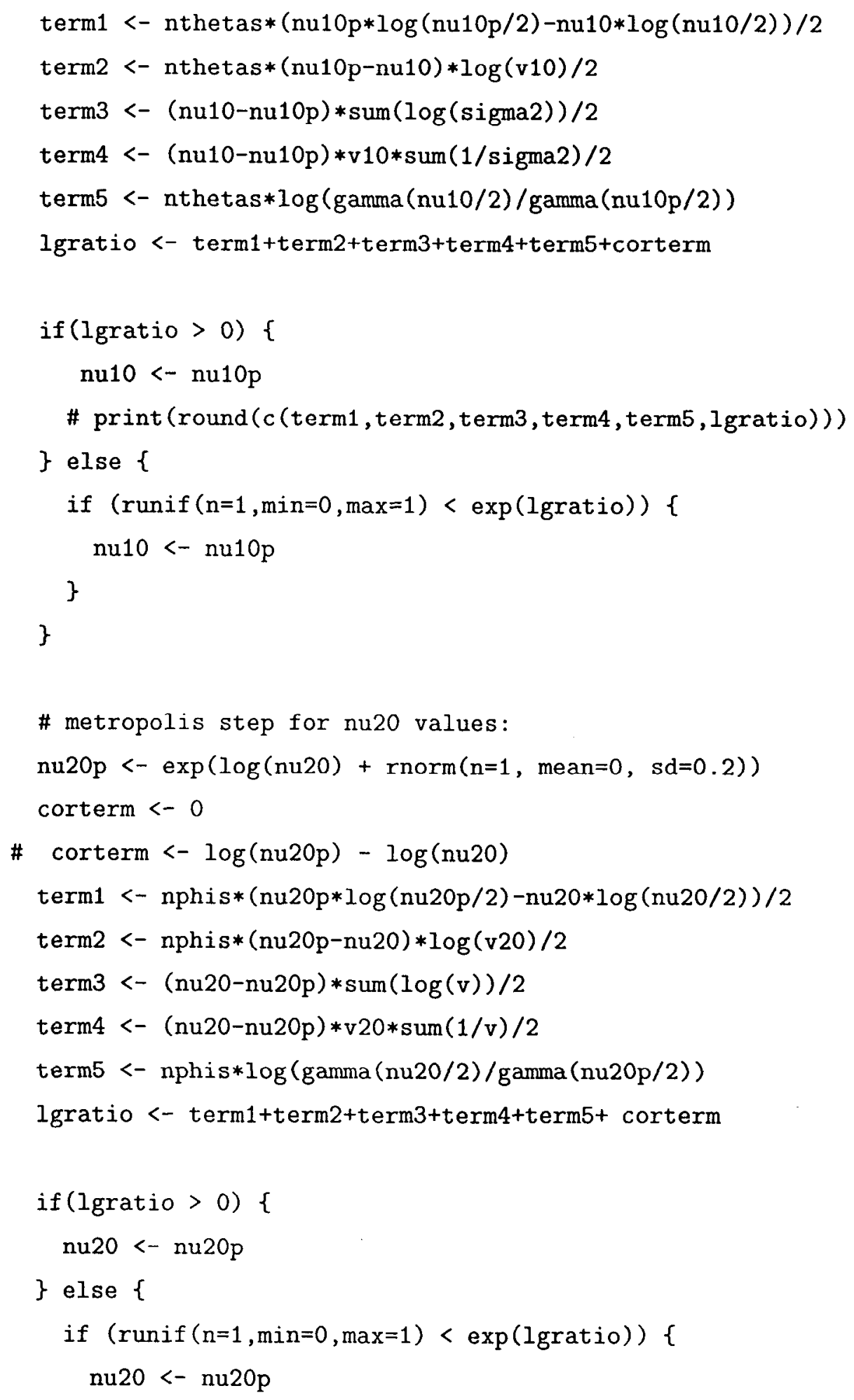




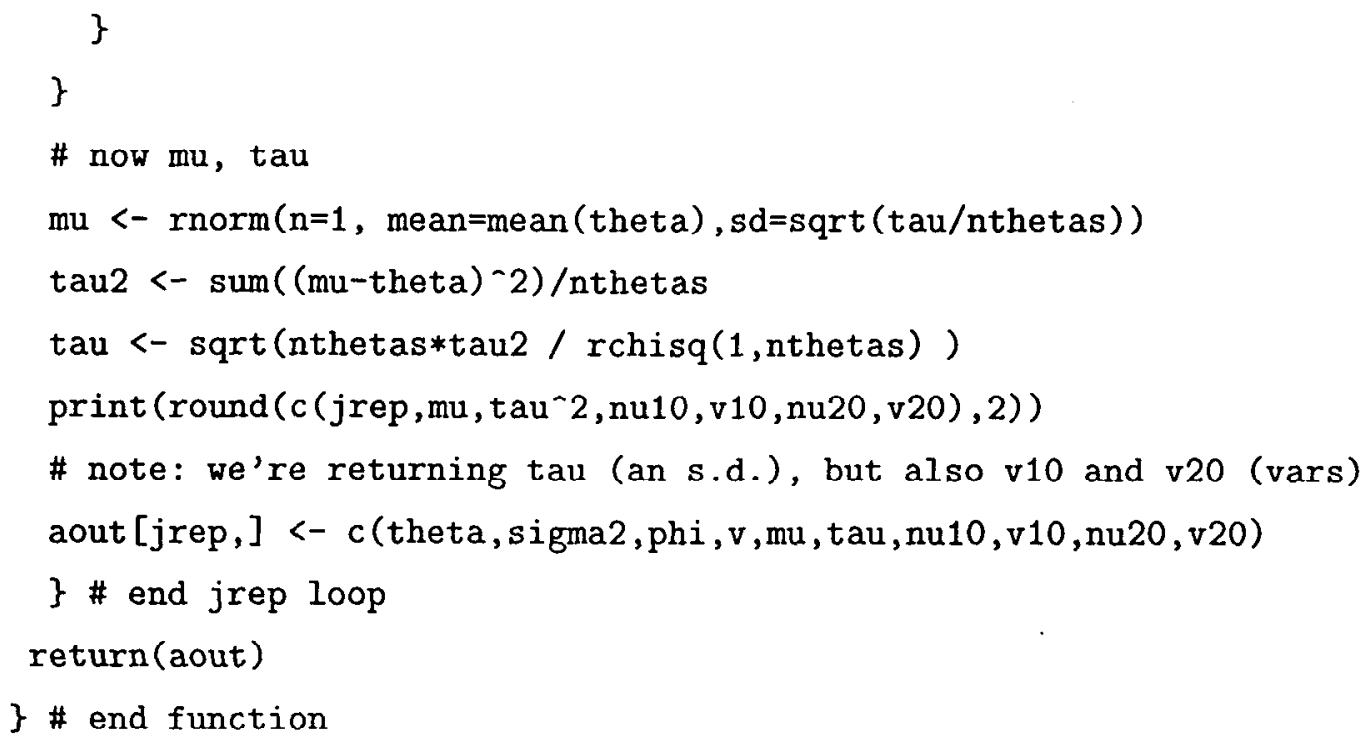

